\title{
e The Impact of Comparative Effectiveness Research on Interventional Pain Management: Evolution from Medicare Modernization Act to Patient Protection and Affordable Care Act and the Patient-Centered Outcomes Research Institute
}

Laxmaiah Manchikanti, MD1, Frank J.E. Falco, MD², Ramsin Benyamin, MD², Standiford Helm II, MD ${ }^{4}$, Allan T. Parr, MD ${ }^{5}$, and Joshua A. Hirsch, MD

From: ${ }^{2}$ Pain Management Center of Paducah, Paducah, KY; ${ }^{2}$ Mid Atlantic Spine \& Pain Physicians of Newark, Newark, DE; ${ }^{3}$ Millennium Pain Center, Bloomington, IL; 4Pacific Coast Pain Management Center, Laguna Hills, California; sPremier Pain Center, Covington, LA; ${ }^{6}$ Massachusetts General Hospital and Harvard Medical School, Boston, MA.

Dr. Manchikanti is Medical Director of the Pain Management Center of Paducah, Paducah, KY, and Associate Clinical Professor, Anesthesiology and Perioperative Medicine, University of Louisville, Louisville, KY. Dr.

Falco is Medical Director of the Mid Atlantic Spine \& Pain Physicians of Newark, Neward, DE; Director, Pain Medicine Fellowship, Temple University Hospital, Philadelphia, PA and Associate Professor, Department of PM\&R, Temple University Medical School, Philadelphia, PA Dr. Benyamin is the Medical Director, Millennium Pain Center, Bloomington, IL, and Clinical Assistant Professor of Surgery, College of Medicine, University of Illinois, Urbana-Champaign, IL. Dr. Helm is Medical Director, Pacific Coast Pain Management Center, Laguna Hills, CA. Dr. Par is Medical Director of Premier Pain Center, Covington, LA. Dr. Hirsch is Chief of Minimally Invasive Spine

Surgery, Depts. of Radiology and Neurosurgery, Massachusetts Genera Hospital and Associate Professor of Radiology, Harvard Medical School, Boston, MA.

Address Correspondence: Laxmaiah Manchikanti, M.D. 2831 Lone Oak Road

Paducah, Kentucky 42003 E-mail: drlm@thepainmd.com

Full disclosures on p. E273. Manuscript received: $04 / 21 / 2011$ Accepted for publication: 05/06/2011
The Patient-Centered Outcomes Research Institute (PCORI) was established by the Affordable Care Act of 2010 to promote comparative effectiveness research (CER) to assist patients, clinicians, purchasers, and policy-makers in making informed health decisions by advancing the quality and relevance of evidence concerning the manner in which diseases, disorders, and other health conditions can effectively and appropriately be prevented, diagnosed, treated, monitored, and managed through research and evidence synthesis.

The development of PCORI is vested in the Medicare Modernization Act (MMA) and the American Recovery and Reinvestment Act (ARRA). The framework of CER and PCORI describes multiple elements which are vested in all 3 regulations including stakeholder involvement, public participation, and open transparent decision-making process. Overall, PCORI is much more elaborate with significant involvement of stakeholders, transparency, public participation, and open decision-making. However, there are multiple issues concerning the operation of such agencies in the United States including the predecessor of Agency for Healthcare Research and Quality (AHRQ), the Agency for Healthcare Policy and Research (AHCPR), AHRQ Effectiveness Health Care programs, and others.

The CER in the United States may be described at cross-roads or at the beginnings of a scientific era of CER and evidence-based medicine (EBM). However the United States suffers as other countries, including the United Kingdom with its National Health Services (NHS) and National Institute for Health and Clinical Excellence (NICE), with major misunderstandings of methodology, an inordinate focus on methodological assessment, lack of understanding of the study design (placebo versus active control), lack of involvement of clinicians, and misinterpretation of the evidence which continues to be disseminated.

Consequently, PCORI and CER have been described as government-driven solutions without following the principles of EBM with an extensive focus on costs rather than quality. It also has been stated that the central planning which has been described for PCORI and CER, a term devised to be acceptable, will be used by third party payors to override the physician's best medical judgement and patient's best interest. Further, stakeholders in PCORI are not scientists, are not balanced, and will set an agenda with an ultimate problem of comparative effectiveness and PCORI that it is not based on medical science, but rather on political science and not even under congressional authority, leading to unprecedented negative changes to health care. Thus, PCORI is operating in an ad hoc manner that is incompatible with the principles of evidence-based practice.

This manuscript describes the framework of PCORI, and the role of CER and its impact on interventional pain management.

Key words: Patient-Centered Outcomes Research Institute (PCORI), comparative effectiveness research (CER), National Institute for Health and Clinical Excellence (NICE), Patient Protection and Affordable Care Act (ACA), Medicare Modernization Act (MMA), American Recovery and Reinvestment Act (ARRA), interventional pain management, interventional techniques, evidencebased medicine, systematic reviews.

Pain Physician 2011; 14:-E249-E282 


\title{
The most entrenched conflict of interest in medicine is a disinclination to reverse a
}

\author{
previous opinion (1). Yudkin, Richter, Gale. Lancet 2011; 377:1220-1222.
}

The Patient-Centered Outcomes Research Institute (PCORI) was established by the Patient Protection and Affordable Care Act of 2010 (ACA) as a major new program for comparative clinical effectiveness research. It is a private non-profit, tax-exempt corporation, to "assist patients, clinicians, purchasers, and policy-makers in making informed health decisions by advancing the quality and relevance of evidence concerning the manner in which diseases, disorders, and other health conditions can effectively and appropriate be prevented, diagnosed, treated, monitored, and managed through research and evidence synthesis (2-5)." The ACA's directive that the institute, "shall enter into contracts for the management of funding and conduct of research with government agencies and academic or private sector research entities and that it shall give preference to the Agency for Healthcare Research and Quality (AHRQ) and National Institutes of Health (NIH)," forces the use of failed policies. It creates a politically-driven program with the attendant dangers of central planning and Recipients of healthcare services are at risk of having stakeholders who are not scientists or physicians setting the final agenda, using political and financial, rather than medical, criteria. The entity would be without congressional oversight, freeing it from the usual checks and balances (2-7). Unfortunately, PCORI is functioning in an ad hoc manner, with a history of using process to determine outcomes that are incompatible with evidence-based practice even in the opinion of most liberal politicians or scientists, leading to unprecedented negative consequences of health care and credibility of evidence-based medicine.

On March 23, 2010, President Obama signed into law the most sweeping health care system reform legislation since Medicare was enacted in 1965 (2-4). The ACA is not only historic and transformational, but profoundly troubling for some and controversial for many (2-8). Whatever the future of the ACA, legislatively or judicially, its impact will be long lasting in many forms - including the practice of medicine. While the ACA may make health insurance available to an additional 34 million Americans (4), it does not provide the coverage for many individuals and may detrimentally affect others, and the regulatory environment will adversely affect the practice of medicine (9). It has been state that professional independence could be affected by funda- mentally altering the relationship between individual Americans and the federal government $(7,9)$.

The ACA established two independent and independently funded boards to control costs. The Independent Payment Advisory Board's (IPAB) task is to implement target growth rates for Medicare, while the PCORI task is to evaluate and apply effectiveness research (CER) $(2-4,10,11)$.

The major impact of the ACA on physicians is related to these 2 boards. The IPAB has been described by the president as the Medicare Payment Advisory Commission (MedPAC) on steroids. Thus, the PCORI focus on CER may, in an analogous manner, be described as AHRQ on steroids. The intent underlying the formation of the two panels is that they will, with their comingled effects on what care can be provided and what will be paid, provide high quality care at a reasonable cost. The reality is that neitherof them will be practical or appropriate. In fact, while gains may be none to modest based on administrations and Congressional Budget Office's (CBO) projections, the permanent deleterious effects and regulatory influence with extended costs will be enormous measured in dollars, but more so in declining quality, access, complicated delivery system, and finally without any change or increase in costs. Recently the Institute of Medicine (IOM), another organization within the Department for Health and Human Services (HHS), has provided a recommendation that the PCORI, should be the central organization to provide CER (9), independent from congressional oversight (12). This absence of check or balance creates the possibility of uncontrolled regulatory activism.

The supporters of the PCORI and ACA continue to tout the advantages of the PCORI and CER and its components including the methodological committee (11-18). The supporters of the PCORI believe this research could educate patients and help them make better medical decisions. It is true that this organization indeed could foster patient education and benefit patients and doctors. In a 2008 report exploring ways to reduce health care costs, the CBO wrote that CER, "would gradually generate modest changes in medical practice as providers responded to evidence on the effectiveness of alternative treatments, the net effect of which would be to reduce total spending on health 
care in the United States by an estimated $\$ 8$ billion from 2010 to 2019 (or by less than $1 / 10$ of $1 \%$ ) (19). Thus, CER would generate some savings, but not nearly enough to support the industry budget of over $\$ 2$ trillion a year. Further, this analysis does not take into consideration the regulatory costs and stifling effect analysis of bureaucracatic oversight on the practice of medicine. In addition, in an earlier report, the $\mathrm{CBO}$ wrote that for CER to significantly decrease spending, the government would probably need, "additional legislative authority to allow the program to consider relative benefits and costs in a more extensive way and to modify the financial incentives facing doctors and enrollees accordingly (20).

President Obama has promised that CER won't lead to rationing. However, Donald Berwick, MD, the recess appointmee as the Admistrator of the Centers for Medicare and Medicaid Services (CMS), the organization within which PCORI exists, has expressed lavish praise for National Institute for Health and Clinical Excellence (NICE) and its restrictions on care. In a 2009 interview with Biotechnology Healthcare, Dr. Berwick said NICE has "developed very good and very disciplined, scientifically grounded, policy-connected models for the evaluation of medical treatments from which we ought to learn" (21). Consequently, the PCORI either is America's NICE or could easily become one.

In contrast to the supporters (6), opponents state that CER is not a medical science, but a political science and will be detrimental to health care with its potential dangers of cost emphasis and centralization which will be used by payors to override the physician's best medical judgement and patient's values. Further, the ACA and PCORI are not interested in working on intricate issues of CER, the appointment process, methodologic quality assessment, the cost, and its eventual non-effectiveness. It appears that the basic concept that everything should be performed based on CER or evidence-based medicine (EBM), is not applied to these regulations (11-18). In an editorial in Lancet (22) authors write about guiding the guidelines complimenting the IOM's 2 complementary sets of standards to improve the quality of systematic reviews and clinical practice guidelines $(12,23)$. The potential harm from the PCORI depends on how the research is used, which could easily quell medical innovation by centralizing care. The fear is that officials seeking to control costs would use this research to restrict access to more costly medical interventions as done by NICE. As the government puts more people into the US health care system and the promised savings, fail to materialize, there will be tremendous pressure on elected officials to slow spiraling costs, which can reduce access and quality.

Every guideline, editorial, and article repeats the same issues that clinicians can be overwhelmed by the quantity of reported clinical evidence, and often need to rely on aggregated evidence to guide decision-making. But, after spending millions of dollars they recommended 21 standards to systematic reviews and 8 for guidelines, which probably will never be followed even by the makers of IOM guidelines. Further, these are not new, these are already available in the literature such as Preferred Reporting Items for Systematic Reviews and Meta-analyses (PRISMA), Quality of Reporting of Meta-analyses (QUOROM), Consolidated Standards of Reporting Trials (CONSORT), Strengthening of Reporting of Observational Studies in Epidemiology (STROBE), and Meta-analysis of Observational Studies in Epidemiology (MOOSE) (24-41). The same investigators and agencies have provided the same or similar guidelines with previous failures such as the Agency for Healthcare Policy and Research (AHCPR) and the birth of AHRQ (42-45). It also has been suggested that CER needs incentivizing and centralizing (46). Further, despite PCORI the billions to be spent on CER, there are advocates who continue to recommend that an additional independent organization should be created that would work with multiple stakeholders to develop guidelines potentially to improve their quality (47). These authors, without evaluating the guidelines properly and by looking at only the headlines, concluded that guidelines from NICE were more rigid and appropriate than AHRQ guidelines which provided more autonomy.

In the United States similar to England, numerous publications have come and gone with changing concepts increasing only the costs of implementation in an ad hoc manner. This increasing cost of implementation is incompatible with evidence-based practice, yet promoted as EBM. These include IOM standards of patient safety (48-60), AHCPR guidelines (42-45), issues related to infection control and implementation of safe injection practices (61-67), and yhe well known mammography guideline fiasco $(68,69)$, ever-changing recommendations of hormone therapy $(70,71)$, and American College of Occupational and Environmental Medicine (ACOEM), American Pain Society (APS), Official Disability Guidelines (ODG), and Washington State Authority guidelines (30-41,71-76). We live in a world in which nurses spend time educating patients who are intubat- 
ed and unconscious about the risk of falls because such eduction is a marker of quality.

Further, methodologists tend to ignore the fundamental principles of methodology and clinical relevance and more importantly patient preferences in production of guidelines $(38,39,77,78)$. These concepts can lead to unsubstantiated cost savings (79). In a manuscript evaluating CER and its ability to pay for itself, Elshaug and Garber (79) have projected an $80 \%$ savings in costs associated with vertebroplasty and kyphoplasty by eliminating the use of these two procedures on the evidence derived from 2 poor quality randomized trials, that were published in the New England Journal of Medicine (79-81). The literature is replete with numerous examples of such abuses in EBM and CER literature which may be leading to thr PCORI and may exceed abuses in practices of medicine - the former leading to severe restrictions of access, significant rationing in health care, and the latter leading to overuse and abuse.

\subsection{Evolution of the Concept of Comparative Effectiveness Research}

Despite the controversy surrounding comparative effectiveness over the past several years, as evinced by the multitude of publications, both for and against, which the field has inspired over the years, CER has become the most celebrated research initiative in medicine in the United States. However, CER has been practiced too long considered a new concept or standard of practice, with its intellectual roots being traced back to mid eighteenth century Scotland and "arithmetical medicine" practiced by the graduates of Edinburgh Medical School $(38,39,82)$. The first comparative effectiveness study, in fact, was initiated by James Lind who undertook a controlled trial of 6 separate treatments for scurvy (82). In the United States, the first use for CER has been attributed to Ernest Codman, at the beginning of the twentieth century, with his founding of "outcomes management" in patient care (83).

CER is defined by the IOM (84) as, "the generation and synthesis of evidence that compares the benefits and harms of alternative methods to prevent, diagnose, treat, and monitor a clinical condition, or to improve the delivery of care." This is not significantly different from the definition of EBM which is defined as, "the conscientious, explicit, and judicious use of current-best evidence of making decisions about the care of individual patients" (85). While EBM is focused upon the use of the right type and extent of knowledge to guide the right and good intentions and actions of medical practice, which is fundamental to the prudential clinical decision-making (31), CER, in contrast, is aimed at assisting consumers, clinicians, purchasers, and policy-makers to make informed decisions that will improve health care at both the individual and population levels. Thus, EBM and CER not only share many similarities and goals, but they appear to be one and the same specifically under the new regulations $(12,23,31-39,86-90)$.

While the present attention is focused on the ACA of 2010, the American Recovery and Reinvestment Act (ARRA) of 2009, and President Obama for CER, it started long before 2009, with passage of the Medicare Modernization Act (MMA) in 2003 (2-4,38,91-93). The U.S. government has a rather long, but somewhat checkered, history of involvement in CER and related efforts. Further, CER and its impact has been felt in European countries prior to the United States.

The 1930s saw the development of health services research in a world increasingly obsessed with egalitarian uniformity. Subsequently, in the 1970s and 1980s, following several decades of socialized health care in the United Kingdom, multiple studies were released that highlighted the wide geographical variations in general medical admissions, including operations such as appendectomy, caesarean section, cholecystectomy, hysterectomy, tonsillectomy, and prostatectomy (94). These variations, while demonstrating the inequities of the National Health Services (NHS), raised multiple questions about the probity and questions about the appropriateness and cost-effectiveness of many of its treatment. Further publications from Archie Cochrane (95) and other researchers $(96,97)$, that such variation meant either under-provision in some places and/or over-provision and possibility ineffective treatment in other regions.

In the United States, federal efforts date at least to the late 1970s and the short-lived National Center for Healthcare Technology. It was established in 1978 as part of the Department of Health, Education, and Welfare (DHEW) and was given a broad mandate to conduct and promote research on health care technology. It included an advisory board appointed by the secretary to assist in setting research priorities. The center sponsored or co-sponsored major evaluations of coronary artery bypass graft surgery, dental radiology, and caesarean delivery, and made about 75 recommendations to the Medicare program about coverage. The center ceased operations at the end of 1981, reflecting changes in priorities for the new administration and 
the Congress, as well as opposition from some provider and industry groups (97).

In 1972, the Office of Technology Assessment (OTA) was created as an advisory agency to Congress, covering a broad set of issues, including health care. Most of the focus on evaluation of technologies now would be called CER. The OTA produced an extensive review and analysis of the issues involved in options for improving evidence about the clinical effectiveness and cost-effectiveness of medical treatments (98). For a variety of reasons - having little to do with its health care study specifically but instead reflecting broader questions about the agency's role, - the OTA was eliminated in 1995.

In 1989, the AHCPR was created as an arm of the HHS (99). AHCPR undertook a number of initiatives, including creation of the National Guideline Clearinghouse (NGC) designed to summarize the available medical evidence on the appropriate treatments for various conditions (99). They produced 15 guidelines at a cost of $\$ 750$ million. In the mid 1990s, controversies arose after an agency-sponsored research team concluded that there was insufficient evidence to support certain spinal surgeries, and on the basis of that, the agency issued practice guidelines for the treatment of back pain (42-45). Strong opposition from spine surgeons, along with broader questions about the value of the research that the agency had funded and other factors, led to pressure to eliminate the agency (45).

Ultimately, AHCPR was retained, but its funding for fiscal year 1996 was reduced and it was renamed the AHRQ. Since then, its overall budget has generally been maintained, at least in nominal terms, or increased (99).

In 2003, the landmark MMA authorized the AHRQ to spend up to $\$ 50$ million in 2004 and additional amounts in future years to conduct and support research with a focus on "outcomes, comparative clinical effectiveness, and appropriateness of healthcare items and services" for Medicare and Medicaid enrollees $(91,100,101)$. The actual funding appropriated for that initiative has been $\$ 15$ million per year. Using that funding, the AHRQ has established an "effective healthcare" program consisting of 3 main functions: reviewing and synthesizing existing evidence (using its evidence-based practice centers; generating new information using a set of approved research centers (such as the HMO research network) that have access to data from medical claims and electronic medical records, and publishing findings and formats that are geared to the differing needs of clinicians, patients, and policy-makers (102).
Other federal agencies also engaged in various activities related to CER - efforts that received less attention than the AHRQ's activities, but that are probably larger in dollar terms. The Department of Veterans Affairs has a very substantial research program that reviews evidence from the medical records of its patients, focusing particularly on the clinical effectiveness of treatments. The department also sponsors evidence reviews through the technology assessment program and helps fund clinical trials - including the study comparing strengths of drug therapy. Over the years, the NIH has sponsored a number of trials that compare treatments directly.

The CMS also has helped to sponsor a limited amount of research on comparative effectiveness (i.e., lung volume, reduction surgery). The CMS generally considers only whether devices and procedures are clinically effective in making payment decisions. However, it has sponsored some studies comparing the effectiveness of different treatments but has done so largely to determine whether to establish separate payment rates for similar treatments (103). CMS has sponsored a trial with the NIH that may eventually compare the effects of daily dialysis for kidney patients with the conventional treatment of dialysis 3 times per week. However, this may increase the cost rather than reduce it if daily dialysis proves more effective for certain patients. CMS could modify its payment policy to cover the additional costs of more frequent treatments for those patients.

Overall, it has been estimated that the federal government has spent $\$ 1.5$ billion in 2005 on health services research. This broader category includes some of the work on comparative effectiveness, but also encompasses many other types of studies (104). Further, it also has been stated that aggregate figures may not include all federal funding for comparative trials or other efforts that are outside the traditional scope of health services research.

On February 17, 2009, President Obama signed into law the ARRA. Of $\$ 787$ billion that was appropriated, $\$ 150$ billion was allotted for medical issues, being touted as a down payment on health care reform $(92,93)$. Among the most controversial provisions of the medical spending was the allotment of $\$ 1.1$ billion for CER. Further, multiple bills have been introduced in the 100th U.S. Congress that directly address CER (89).

The ARRA established the Federal Coordinating Council compared to stakeholder groups established by MMA. The ARRA established this council as specified in the law with no more than 15 members appointed 
by the IOM without statutory requirement for broad stakeholder representation on the panel. The MMA in its effective health care programs had stakeholder groups and AHRQ solicited contracts for citizen forum to engage stakeholders in CER activities. This aspect also was funded by ARRA with $\$ 10$ million over 5 years.

The ACA of 2010 (2-5) established the PCORI, a non-profit corporation charged with identifying research priorities, developing a research project agenda , and executing research to better inform patients and physicians on their treatment choices.

Since the passage of the MMA, numerous projects have been developed with the ARRA funding itself which has led to over $\mathbf{4 0 0}$ grants and contracts focused on evidence development, evidence translation and dissemination, and establishment of CER infrastructure and methodologies. Recently the IOM has recommended $(12,23)$ that the PCORI should be pivotal in providing future centralized CER, effectively eliminating the research conducted by clinical practices and clinicians, with a focus on public and private partnerships with private partnerships being academic centers.

\subsection{Patient-Centered Outcomes Research Institute}

The ACA authorizes the PCORI for clinical effectiveness research (2-5). The purpose of the PCORI is to assist patients, clinicians, purchasers, and policy-makers in making informed health decisions by advancing the quality and relevance to evidence (2-5). The ACA specifies that institute, "shall enter into contracts for the management of funding and conduct of research" with government agencies and academic or private sector research entities, and that it "shall give preference to the AHRQ and the NIH" (5).

The ACA lays out a framework for conducting comparative effectiveness reviews that includes several key elements: stakeholder involvement, transparency, public participation, and open decision-making.

The ACA, in some areas, explicitly sets forth certain requirements, whereas in other areas, these requirements are identified in statutes, some of them not yet fully defined, and are addressed on an ongoing basis in the course of implementation of the ACA and PCORI. However, the basic framework has been developed by the Federal Coordinating Council of Comparative Effectiveness Research established through the ARRA. The ARRA established the Federal Coordinating Council for CER to foster optimal coordination of CER conducted, are supported by the federal government. The council consists of 15 members, all of whom must be government employees and at least half of whom must have clinical experience. Writing on the structure of the Federal Coordinating Council of Comparative Effectiveness Research. Ezekiel Emanuel, the brother of former White House Chief of Staff, Rahm Emanuel, and a member of the council (90), in his book Healthcare Guaranteed, wrote, "the Institute for Technology and Outcomes Assessment will provide information on the effectiveness and cost to eliminate tests or treatments of marginal or no value" (105). Further, this council bore a striking resemblance to the agency that assesses comparative effectiveness in Great Britain - NICE. The NICE analyzes both clinical effectiveness and cost effectiveness.

On June 30, 2009, the council released a report to President Barack Obama and Congress on its recommendations for CER funding priorities for the Office of the Secretary $(106,107)$. The council established explicit threshold and prioritization criteria to guide recommendations for funding priorities. The council also developed a strategic framework for categorizing current CER activity, identifying gaps, and informing the recommendations for priorities.

\subsection{Framework of Cer And PCORI}

Since the final development of the PCORI is vested in its origins in the MMA with an intermediary boost from the ARRA, many of the elements are common for all 3 regulations, including stakeholder involvement, transparency, public participation, and open decision making.

\subsection{Stakeholder Involvement}

The stakeholder involvement is described in all 3 legislations, the MMA, ARRA, and ACA. Table 1 illustrates the stakeholder involvement (108). While there are similarities as illustrated in Table 1, there are also differences.

\subsubsection{Medicare Modernization Act}

The MMA requirements are simpler, providing regulation that the $A H R Q$ must insure that there was broad and ongoing consultation with relevant stakeholders in carrying out the program. The statute leaves the AHRQ broad discretion in how it implements this requirement. One of the AHRQ's responses to this general mandate was the formation of an advisory stakeholder group to provide feedback on program initiatives and to serve as a sounding board for interests impacted by CER. Thus far, 3 stakeholder group panels have been formed to advise AHRQ. The first panel met on a quar- 
terly basis from early 2005 to mid 2007, and the second panel met from fall of 2007 through early 2010 (108). The second stakeholder group was organized into multiple workgroups such as product development, program priorities, and product dissemination. The AHRQ solicited nominations for a third stakeholder group in January 2010 which started meeting in the fall of 2010, and will meet for a 2-year period. The AHRQ described the role of the stakeholder group in the federal register (109) as follows:

- Provide guidance and program implementation, including:
- $\quad$ quality improvement;

- opportunities to maximize impact and expand program reach;

- $\quad$ ensuring stakeholder interests are considered and included; and

- $\quad$ evaluating success.

- Provide input on implementing Effective Health Care Program reports and findings in practice and policy settings.

- Identify options and recommend solutions to issues identified by Effective Health Care Program staff.

- Provide input on critical research information gaps

Table 1. Framework for conducting comparative effectiveness reviews: stakeholder involvement.

\begin{tabular}{|c|c|c|}
\hline ACA'S Patient-Centered Outcomes Research & $\begin{array}{c}\text { ARRA'S Comparative Effectiveness } \\
\text { Research }\end{array}$ & $\begin{array}{c}\text { MMA'S } \\
\text { Effective Health Care Program }\end{array}$ \\
\hline $\begin{array}{l}\text { PCORI Board of Governors } \\
-21 \text { members } \\
\text { - AHRQ Director and NIH Director specified in law } \\
\text { - } 19 \text { members appointed by the Comptroller General } \\
\text { - Composition of } 19 \text { appointed members specified } \\
\text { in law: } 3 \text { patient reps/consumers; } 7 \text { physician/pro- } \\
\text { vider reps; } 3 \text { payer reps; } 3 \text { industry reps; } 1 \text { rep for } \\
\text { quality improvement or health service researchers; } \\
2 \text { federal government/state reps } \\
\text { - [Sec. } 1181(\mathrm{f})]\end{array}$ & $\begin{array}{l}\text { Federal Coordinating Council } \\
\text { - specified in law } \\
\text { - "not more than } 15 \text { members, all of } \\
\text { whom are senior Federal officers or } \\
\text { employees with responsibility for } \\
\text { health related programs, appointed by } \\
\text { the President, acting through the Sec- } \\
\text { retary of Health and Human Services" }\end{array}$ & $\begin{array}{l}\text { Stakeholder Group } \\
\text { - not FACA compliant; not required in } \\
\text { law; no votes taken; serves as a sounding } \\
\text { board } \\
\text { - AHRQ is flexible regarding the number } \\
\text { of members } \\
\text { - AHRQ provides only general selec- } \\
\text { tion criteria in public notices soliciting } \\
\text { nominations }\end{array}$ \\
\hline $\begin{array}{l}\text { PCORI Expert Advisory Panels } \\
\text { - may be permanent or ad hoc } \\
\text { - will assist in identifying research priorities, estab- } \\
\text { lishing the research project agenda, and for other } \\
\text { purposes. } \\
\text { Two Required Panels: } \\
\text { 1. Clinical Trials Expert Advisory Panel } \\
\text { 2. Expert Advisory Panel for Rare Disease } \\
\text { Composition of Panels: } \\
\text { - practicing and research physicians, patients, experts } \\
\text { with experience in the topic } \\
\text { - may include a technical expert of each manufactur- } \\
\text { er or each medical technology included in the study }\end{array}$ & $\begin{array}{l}\text { IOM Priority-Setting Committee } \\
\text { - IOM appointed members } \\
\text { - no statutory requirement for broad } \\
\text { stakeholder representation on panel }\end{array}$ & \\
\hline $\begin{array}{l}\text { Support for Patient and Consumer Reps: } \\
\text { - Institute must "provide support and resources" to } \\
\text { help reps participate effectively }\end{array}$ & & \\
\hline $\begin{array}{l}\text { Methodology Committee: } \\
\text { - required by statute } \\
\text { - standing committee } \\
\text { - } 15 \text { members appointed by Comptroller General } \\
\text { - composition: experts in their field; stakeholders } \\
\text { with expertise; Directors of NIH and AHRQ } \\
\text { - function: to develop and improve science and } \\
\text { methods of research by developing and updating } \\
\text { methodological standards } \\
\text { [Sec. } 1181(\mathrm{~d})(6) \text { ] }\end{array}$ & $\begin{array}{l}\text { ARRA Funding: } \\
\text { - } \$ 1.1 \text { billion in CER spending } \\
\text { - ARRA provides funding for AHRQ } \\
\text { Citizen Forum Contract }\end{array}$ & $\begin{array}{l}\text { AHRQ Citizen Forum Contract: } \\
\text { - AHRQ solicited contracts for a Citizen } \\
\text { Forum to engage stakeholders in CER } \\
\text { activities } \\
\text { - funded by ARRA; } \$ 10 \text { million over } 5 \\
\text { years } \\
\text { - contractor selection forthcoming }\end{array}$ \\
\hline
\end{tabular}

Adapted and modified from: Partnership to Improve Patient Care. A Procedural Framework for the Conduct of Comparative Clinical Effectiveness Research. November 2010. www.improvepatientcare.org/sites/default/files/CER_Procedure-PIPC_Whitepaper.pdf (108) 
for practice and policy, as well as research methods to address them, specifically:

- information needs and types of products most useful to consumers, clinicians, and policy makers;

- feedback on Effective Health Care Program reports, reviews, and summary guides;

- $\quad$ scientific methods and applications.

- Champion objectivity, accountability, and transparency in the Effective Health Care Program.

In summary, the stakeholder group does not have a fixed or specified number of members. Its composition included individuals drawn from multiple constituencies presumably impacted by the comparative effectiveness program research, including patients, consumers, and employers. These meetings are held in private (109). Further, there is no formal voting process, and discussions are based both on the AHRQ requests for input and individual member suggestions on all aspects of the program. Further, the stakeholder group is not a formal advisory committee, and is not operated according to the requirements of Federal Advisory Committee Act concerning open meetings (109). In addition, the AHRQ has combined the management of the new stakeholder group with an initiative to increase consumer input into CER operations and processes. It also solicited proposals to establish and support community forums on effective health care to formally engage stakeholders. According to the AHRQ, this initiative is expected to build all the smaller initiatives that has guided the AHRQ's effective health care program and will be an important component for a larger and more sustained national initiative in CER, translation, and use (110). Further, according to the Center for Medical Technology Policy (CMTP), this project has been awarded to the American Institutes for Research (AIR), AcademyHealth, CMTP, and several other organizations under a multiyear, $\$ 10$ million per year contract.

However, the stakeholder groups in the effective health care program and many other aspects of the AHRQ have been mostly silent advisors without implementation of the input from the public, with development of multiple initiatives, which have not been shown to be effective in providing practical CER findings.

\subsubsection{American Recovery and Reinvestment Act}

The ARRA of 2009 made available $\$ 1.1$ billion to accelerate the development and dissemination of CER. Of the $\$ 1.1$ billion, $\$ 300$ million was allocated to the AHRQ, $\$ 400$ million to $\mathrm{NIH}$, and $\$ 400$ million to the Of- fice of the Secretary of HHS for disbursement $(92,93)$.

The ARRA legislation required that a Federal Coordinating Council for CER composed of senior federal officials with responsibility for health-related programs located in the HHS department, the Department of Veterans Affairs, and the Department of Defense be created to guide and coordinate the use of these funds. The legislation also required the IOM to recommend national research priorities for CER conducted or supported by ARRA funds after considering stakeholder input. THe IOM formed a committee for this purpose, funded by a contract with the HHS department.

Finally, there was a 23-person IOM committee which included 3 consumers and patient advocacy representatives in its membership, even though neither the Federal Coordinating Committee nor the IOM committee was required by the ARRA to include stakeholders.

The IOM has published guidance on CER, preparation of guidelines, and standards for systematic reviews, with the obvious conclusion that the PCORI should be the pivotal organization with the AHRQ in conducting and promoting CER.

While there are no stakeholders, the individuals involved in preparation of these guidelines may have significant conflicts of interest which have not been disclosed. They also have numerous interrelationships with organizations related to the $\mathrm{NIH}, I O M, A H R Q$, Economic Cycle Research Institute (ECRI), Research and Development Corporation (RAND), and multiple other organizations.

\subsubsection{Affordable Care Act's Patient-Centered Outcomes Research Institute}

In contrast to the MMA and ARRA, the ACA provides for broad stakeholder participation on both its governing board and its advisory committees. In fact, it appears that the membership has been carefully balanced in composition of the board. However, a critical look at the composition of the board and the lack of congressional oversight on this board illustrates this may not be the case.

The ACA requires the PCORI to have a $21-\mathrm{mem}$ ber board of governors including a specified number of representatives of patients and consumers, physicians and providers, health insurers, medical technology manufacturers, researchers, and government officials. Specifically, it requires 3 representatives from the patient and consumer groups; 4 representatives from the physicians group, one representative from the nurse group, and one representative from the 
integrated health care practitioners group combining for a total of 9 representatives; 4 representatives from government, 3 from insurers, and one from quality improvement and health services researchers, with a total of 8 representatives; 3 representatives from technology manufacturers and development; and one representative from hospitals.

In addition, the law identifies the directors or designees of the AHRQ and NIH as members of the board, it delegates responsibility to the comptroller general to make the other 19 appointments to the board. The board of governors is intended to represent a broad range of perspectives and collectively have scientific expertise. The appointments to the board are made for 6-year terms staggered evenly over 2-year increments, with a limit that no individual shall be appointed for more than 2 terms.

In addition to the primary governing board, the ACA also provides opportunities for the board to make use of both standing and ad hoc expert advisory panels to support the institute's work to identify research priorities, establish the research project agenda, and evaluate other essential needs. These panels also must have broad representation, including patient and provider representatives. The ACA requires that 2 ad hoc expert advisory panels be established. These include a clinical trials panel and a panel for each project related to a rare disease. Further, the ACA also provides statutory direction on the composition of these panels, as well as other expert advisory panels that the board chooses to establish, without setting out precise numbers and composition. However, the law provides the guidance on this issue that these panels must include practicing and research clinicians, patients, and experts in scientific and health services research, health services delivery, and EBM with experience in the topic, and as appropriate, experts in integrative health and primary prevention strategies, somewhat similar to the governing board.

The ACA also requires the establishment of a separate 15-member expert methodology committee to be appointed by the comptroller general to address methodological standards for CER. This panel is required to be composed of the NIH and AHRQ directors or their designatees and experts in their scientific field. The purpose of this provision is that the stakeholders with expertise in various areas may be appointed to this panel, thus not limiting participation to individuals employed by academic research centers. However in practical terms this may not be an issue amenable to clinical specialists to be serving on this committee, and even if that happens, there is no evidence that any such input will be accepted.

While the composition appears to be appropriate, this does not meet the real requirement. Most of the panel experts are methodologists from interest groups of various organizations, thus this may lead to inappropriate decisions or an inability to reach consensus, if in fact there is independence for these members.

\subsection{Transparency}

Transparency has been established the MMA, ARRA, and ACA (Table 2). However multiple regulations written for the MMA related to AHRQ programs and PCORI continue to emerge.

\subsubsection{Medicare Modernization Act}

Under the MMA, effective health care program, meetings of the stakeholder group established by the AHRQ are held on a quarterly basis, however these meeting are closed, and meeting materials are not posted. The AHRQ encourages the public to visit the effective health care program website, and to sign up for LISTSERVS in order to track developments and have opportunities to comment on key questions to draft reports for systematic reviews and to receive notices of general research topics that are underway. Even though there is no statutory requirement for posting of CER reports, it appears that CER studies are posted in a timely manner after their completion, based on the AHRQ policy that all comments will be publicly posted on the effective health care program website within 3 months after a final report is posted.

Much of the information is not transparent including the process and methods used to conduct CER and the AHRQ's effective health care program. The only information provided is with the publication of the final reports.

\subsubsection{American Recovery and Reinvestment Act}

Working meetings of the Federal Coordinating Committee and IOM priorities committee have been held in private, though the public was asked to provide input for consideration. The Federal Coordinating Committee was eliminated by the ACA. The IOM committee that established CER priorities for the ARRA funding completed its business when its report was issued on June 30, 2009. 
Table 2. Framework for conducting comparative effectiveness reviews: transparency.

\begin{tabular}{|c|c|c|}
\hline $\begin{array}{c}\text { ACA'S Patient-Centered Outcomes } \\
\text { Research }\end{array}$ & $\begin{array}{l}\text { ARRA'S Comparative Effectiveness } \\
\text { Research }\end{array}$ & $\begin{array}{c}\text { MMA'S } \\
\text { Effective Health Care Program }\end{array}$ \\
\hline $\begin{array}{l}\text { PCORI Board of Governors Meetings } \\
\text { - meets in public at call of the Chair or a } \\
\text { majority of members } \\
\text { - public notice requirement for meetings (at } \\
\text { least } 7 \text { days advance notice) }\end{array}$ & $\begin{array}{l}\text { Federal Coordinating Council and IOM } \\
\text { Committee Meetings } \\
\text { - working meetings were not open to the } \\
\text { public } \\
\text { - meeting summaries were included in the } \\
\text { report of the Council } \\
\text { - stakeholder input was solicited by both } \\
\text { the Council and the IOM panel }\end{array}$ & $\begin{array}{l}\text { Stakeholder Group Meetings } \\
- \text { meets in private at call of AHRQ }\end{array}$ \\
\hline $\begin{array}{l}\text { Public Availability of Information via Internet } \\
\text { Website } \\
\text { - required by statute, includes the following: } \\
\text { Research Findings: } \\
\text { - must be made available to clinicians, pa- } \\
\text { tients, and the general public within } 90 \text { days } \\
\text { of the conduct or receipt of findings }\end{array}$ & $\begin{array}{l}\text { Federal Coordinating Council } \\
\text { - posted final report on HHS web site } \\
\text { IOM Committee } \\
\text { - posted stakeholder open meeting pre- } \\
\text { sentations and final report on the IOM } \\
\text { website } \\
\text { ARRA Contract Solicitations and Funding } \\
\text { Awards: } \\
\text { - posted on AHRQ and NIH websites }\end{array}$ & $\begin{array}{l}\text { Public Availability of Information via Inter- } \\
\text { net Website } \\
\text { - no statutory requirement } \\
\text { Research Findings: } \\
\text { - AHRQ EHC practice is to post research } \\
\text { reports, and to notify interested parties of } \\
\text { developments through Listservs }\end{array}$ \\
\hline $\begin{array}{l}\text { Process and Methods for Conduct of Research: } \\
\text { - identity of the research entity and the investi- } \\
\text { gators conducting the research } \\
\text { - conflicts of interest } \\
\text { - direct or indirect links to industry } \\
\text { - research protocols } \\
\text { - other information the Institute determines } \\
\text { appropriate }\end{array}$ & & $\begin{array}{l}\text { Process and Methods for Conduct of } \\
\text { Research: } \\
\text { - MMA Sec. 1013(a)(3)(D)(i) requires "all } \\
\text { scientific evidence relied upon and the } \\
\text { methodologies employed" to be made } \\
\text { publicly available "so that the results...can } \\
\text { be evaluated or replicated" } \\
\text { - AHRQ EHC practice is not to post the } \\
\text { identity of the research entity and the inves- } \\
\text { tigators conducting the research }\end{array}$ \\
\hline $\begin{array}{l}\text { Notice of Public Comment Periods: } \\
\text { - includes posting deadlines for public } \\
\text { comments } \\
\text { Comments Received During Public Comment } \\
\text { Periods } \\
\text { Institute Proceedings }\end{array}$ & & $\begin{array}{l}\text { Notice of Public Comment Periods: } \\
\text { - AHRQ EHC practice is to post information } \\
\text { on the review process and notify interested } \\
\text { parties of opportunity to comment via } \\
\text { Listservs } \\
\text { Comments Received During Public Comment: } \\
\text { - AHRQ EHC practice is to solicit public sug- } \\
\text { gestions for research proposals, post sug- } \\
\text { gestions, and to post comments (and report } \\
\text { authors' responses to comments) within } 3 \\
\text { months after a final report is posted } \\
\text { Stakeholder Group Proceedings: } \\
\text { - AHRQ EHC practice is not to post meeting } \\
\text { agendas, minutes, or proceedings of these } \\
\text { meetings }\end{array}$ \\
\hline $\begin{array}{l}\text { Peer Reviewers: } \\
\text { - a list of those contributing to any peer review } \\
\text { process shall be made public and included in } \\
\text { annual reports } \\
\text { - PCORI may utilize the peer review processes } \\
\text { of contractors or other entities, as well as } \\
\text { medical journals }\end{array}$ & & $\begin{array}{l}\text { Peer Reviewers: } \\
\text { - peer reviewers for systematic reviews are } \\
\text { noted in the Appendix of Final Reports and } \\
\text { posted on the website - published reports, } \\
\text { including DEcIDE network reports, have } \\
\text { been subject to peer review processes of the } \\
\text { applicable journal }\end{array}$ \\
\hline
\end{tabular}

Adapted and modified from: Partnership to Improve Patient Care. A Procedural Framework for the Conduct of Comparative Clinical Effectiveness Research. November 2010. www.improvepatientcare.org/sites/default/files/CER_Procedure-PIPC_Whitepaper.pdf (108) 


\subsubsection{Affordable Care Act's Patient-Centered Outcomes Research Institute}

The ACA requires the PCORI board of governors to meet in public at the call of the chair or a majority of its members. The law also specifies that at least 7 days advance notice must be given for these meetings. Thus, the law is much stricter and more transparent than either the ARRA or MMA, but it continues to be silent on whether agendas and other meeting materials must be posted, and whether other standing or ad hoc committees established by the board must meet in public.

The law requires the PCORI to use an Internet website to keep the public informed of its activities and encourage participation, including posting of the institute's proceedings, and research findings within 90 days of the completion or receipt of reports. Further, the public must be informed of comment periods and deadlines, and comments that have been submitted by the public must be provided.

Further, ACA requires transparency in the process and methods used by the institute to conduct CER. It specifically requires the institute to identify the research entity and the investigators conducting CER, the research protocols used, any conflicts of interest of these parties, and any other information the institute determines to be appropriate.

While these aspects of the ACA and PCORI appear laudable, these are not substantially different from many other federal agencies. The data may be collected and opinions may be given, yet the decisions are made in the same fashion by members of the federal government.

\subsection{Public Participation}

Public participation is considered pivotal in health care reform. However, the ACA, in its debate throughout and various regulatory initiatives have not taken into consideration the public participation as a major issue at its core, even though it appears on the paper that public participation is not only important, but mandatory. Table 3 illustrates the differences between the MMA, ARRA, and PCORI on various aspects of public participation. As expected, public participation is more significant with the PCORI, even though, it may still be inadequate and impractical.

\subsubsection{Medicare Modernization Act}

The AHRQ has taken various steps to engage the public in identifying research priorities for CER including a public listening session in May of 2004. Following these evaluations, the HHS secretary identified an ini- tial set of 10 priority conditions focusing on the needs of the Medicare population in December of 2004. There was also a second listening session which was held on January 11, 2006, leading to the expansion in 2008 of the CER priorities to 14 conditions including conditions also relevant to Medicaid and State Child Health Insurance Program (SCHIP) programs.

The AHRQ also has encouraged public participation in effective health care program activities by encouraging the public to submit research topics for CER projects, by establishing a 4-week public comment period for all draft reports, and by posting for comment the key questions for systematic reviews performed by evidencebased practice centers. However, there has not been any transparency with regards to the AHRQs disclosure of the research center or individual researchers undertaking specific CER studies. Further, public comments are solicited for CER key questions and draft reports that are systematic reviews of the literature on a given topic, however, AHRQ does not permit public comment on projects undertaken by the Effective Health Care Programs Developing Evidence to Inform Decisions about Effectiveness (DECIDE) research network. These research centers generate new scientific information to fill knowledge gaps or just methodological issues as opposed to performing systematic reviews of existing literature. These research abstracts are posted for the public, even though the AHRQ does not post or solicit public comment on draft key questions for this research, and does not post draft final reports for comment.

\subsubsection{American Recovery and Reinvestment Act}

The ARRA called for a 15-member coordinating council. The membership on the council was specified in the law to included representatives from the various federal agencies engaged in CER; however, there was no public participation. The council held 3 listening sessions to receive public comments which were also solicited through the HHS website for the Recovery Act.

The ARRA directed HHS to contract with the IOM to prepare a report on national priorities for CER conducted. The ARRA also specified that the IOM committee must consider input from "stakeholders" in identifying national priority topics for CER.

Under ARRA funding, multiple meetings were held and numerous speeches were heard with numerous suggestions leading to identification of 100 priority topics for CER. However, since the decision-making solely rests on government officials, the importance of public participation has been questioned. 
Table 3. Framework for conducting comparative effectiveness reviews: public participation.

\begin{tabular}{|c|c|c|}
\hline $\begin{array}{c}\text { ACA'S Patient-Centered Outcomes } \\
\text { Research }\end{array}$ & $\begin{array}{l}\text { ARRA'S Comparative Effectiveness } \\
\text { Research }\end{array}$ & $\begin{array}{c}\text { MMA'S } \\
\text { Effective Health Care Program }\end{array}$ \\
\hline $\begin{array}{l}\text { Public Comment Period } \\
-45 \text { - } 60 \text { days comment period required by } \\
\text { statute for: } \\
\checkmark \text { national priorities } \\
\checkmark \text { research project agenda } \\
\checkmark \text { methodological standards } \\
\checkmark \text { peer review process } \\
\checkmark \text { draft findings for systematic reviews }\end{array}$ & & $\begin{array}{l}\text { Public Comment Period } \\
-4 \text { week comment period established by } \\
\text { AHRQ/EHC Program for: } \\
\checkmark \text { Key Questions (for systematic reviews only) } \\
\checkmark \text { Draft Reports (both systematic reviews and } \\
\text { DEcIDE Network reports) }\end{array}$ \\
\hline \multirow[t]{2}{*}{$\begin{array}{l}\text { Forums } \\
\text { - required to increase public awareness and } \\
\text { obtain and incorporate public input and } \\
\text { feedback on research priorities, research } \\
\text { findings, and other duties, activities, or pro- } \\
\text { cesses the Institute determines appropriate }\end{array}$} & $\begin{array}{l}\text { Federal Coordinating Council } \\
\text { - } 3 \text { public listening sessions } \\
\text { - received comments filed through the } \\
\text { public website for } 2 \text { months } \\
\text { - posted interim working documents for } \\
\text { feedback: } \\
\checkmark \text { definition of CER } \\
\checkmark \text { prioritization criteria } \\
\checkmark \text { strategic framework } \\
\text { - open door meetings held to inform } \\
\text { deliberations }\end{array}$ & $\begin{array}{l}\text { Public Meetings } \\
\text { - comments were solicited and reviewed, and } \\
\text { listening sessions were held on identifying } \\
\text { research priorities } \\
\text { - final decisions were made by an HHS } \\
\text { committee } \\
\text { - no public comment on HHS committee } \\
\text { determination }\end{array}$ \\
\hline & $\begin{array}{l}\text { IOM Priority-Setting Committee } \\
\text { - legislation required priorities to be based } \\
\text { on "input from stakeholders" } \\
\text { - three avenues: } \\
\checkmark \text { direct correspondence with the } \\
\text { committee } \\
\checkmark \text { written and oral presentations at an open } \\
\text { stakeholder's meeting } \\
\checkmark \text { submission of specific CER topics } \\
\end{array}$ & \\
\hline $\begin{array}{l}\text { Other Consultations } \\
\text { - Methodology Committee may consult } \\
\text { with relevant stakeholders to carry out its } \\
\text { activities } \\
\text { [Sec. } 1181(\mathrm{~d})(6)(\mathrm{D})] \\
\text { - Process of Developing and Updating Meth- } \\
\text { odological Standards } \\
\checkmark \text { include input from experts, stakeholders, } \\
\text { and decision makers } \\
\checkmark \text { provide opportunity for public comment }\end{array}$ & & \\
\hline
\end{tabular}

Adapted and modified from: Partnership to Improve Patient Care. A Procedural Framework for the Conduct of Comparative Clinical Effectiveness Research. November 2010. www.improvepatientcare.org/sites/default/files/CER_Procedure-PIPC_Whitepaper.pdf (108)

\subsubsection{Affordable Care Act's Patient-Centered Outcomes Research Institute}

The ACA provides a series of detailed specifications for engaging the public in the PCORI's operations. It specifies that a public comment period of between 45 and 60 days must be used in several areas including setting national priorities for CER, establishing a CER project agenda, determining methodological standards for CERs, developing a peer review process, and arriving at findings for systematic reviews.

Further, the ACA also specifies that the PCORI should consider making use of public forums to increase public awareness of its operations and to incorporate public input into its activities. Further requirements include that the methodology committee consult with relevant stakeholders as it carries out it duties. It specifically requires that the process of developing and updating methodological standards must include input from experts, stakeholders, and decision-makers, as well as an opportunity for public comment.

Since the composition of the committees appears to be heavily focused on methodologists, very little direction can be provided by other stakeholders. 


\subsection{Open Decision-Making}

In a democratic society open decision-making must be a rule, not an option. However, it appears that many of the decisions are made behind closed doors without public input. Further, when public input is required, it is not taken into consideration. As illustrated in Table 4, open decision-making has been appropriated for all 3 legislations with significant variations among them.

\subsubsection{Medicare Modernization Act}

The program decisions made by the AHRQ concerning the CER program are not readily identifiable, except as part of documents prepared for Congress. Thus, it is not clear to members of the public how research priorities are determined, how decisions are made to fund specific CER projects, and why public comments are solicited and considered for some CER projects and not others. In addition, there is no information on how nonpublic meetings with particular stakeholder groups impact agency decision-making.

\subsubsection{American Recovery and Reinvestment Act}

The Federal Coordinating Council has submitted its meeting reports to the president and congress. The IOM report on priorities for CER provides information on the panel's decision-making process. Even though the ARRA requires the HHS secretary and directors of $\mathrm{NIH}$ and AHRQ to submit an operating plan for the CER funds appropriated to the Appropriations Committee of Congress that detail the type of research being conducted and priority conditions addressed, these reports provide only general information on the priorities addressed. Thus the issue of open decision-making is non-existent.

\subsubsection{Affordable Care Act's Patient-Centered Outcomes Research Institute}

The ACA requires decisions of the PCORI board to be made in public, by majority vote. The law also specifies that there will be votes on national priorities for CER, the CER research project agenda, methodological standards for CER, and the CER peer review process. However, the law does not address the decisions-making process for standing in ad hoc committees of the board of governors, leaving numerous questions on the open decision-making process and the commitment of the ACA in this aspect.

\subsection{Issues Related to Pcori and Cer}

The issues related to the PCORI and CER are intertwined. The process that the federal agencies and private sector organizations use to set research priorities is central to the benefit that patients, physicians, and others will receive from the investment in this project by Congress, however without any oversight. Multiple priorities have been described by various organizations. The key elements in the priority setting processes include stakeholder involvement and participation, transparency, public participation with a range of input opportunities, particularly from patients and consumers, with clinical input and guidance throughout the process; and open decision-making with systematic input by decision-makers of information received.

\subsection{Stakeholder Involvement}

The major element of an acceptable process is the inclusion of all interested and affected stakeholders. In its 1992 report, the IOM offered among its guiding principles that the process must be sensitive to political con-

Table 4. Framework for conducting comparative effectiveness reviews: open decision-making.

\begin{tabular}{|c|c|c|}
\hline $\begin{array}{l}\text { ACA'S Patient-Centered Outcomes } \\
\text { Research }\end{array}$ & $\begin{array}{l}\text { ARRA'S Comparative Effectiveness } \\
\text { Research }\end{array}$ & $\begin{array}{c}\text { MMA'S } \\
\text { Effective Health Care Program }\end{array}$ \\
\hline $\begin{array}{l}\text { PCORI Board of Governors } \\
- \text { specifies votes on: } \\
\checkmark \text { national priorities } \\
\checkmark \text { research project agenda } \\
\checkmark \text { methodological standards } \\
\checkmark \text { peer review process } \\
\text { [Sec. } 1181(\mathrm{~d})(9) \text { ] }\end{array}$ & $\begin{array}{l}\text { Federal Coordinating Council; IOM Priority- } \\
\text { Setting Committee } \\
\text { - decisions were not made in public } \\
\text { - NIH took steps to obligate ARRA funds } \\
\text { prior to publication of IOM priorities }\end{array}$ & $\begin{array}{l}\text { Stakeholder Group } \\
\text { - advisory group } \\
\text { - provides sounding board }\end{array}$ \\
\hline $\begin{array}{l}\text { Voting } \\
\text { - decisions made by majority vote } \\
{[\text { Sec. } 1181(\mathrm{~d})(9)]}\end{array}$ & & $\begin{array}{l}\text { Voting } \\
\text { - no votes taken }\end{array}$ \\
\hline
\end{tabular}

Adapted and modified from: Partnership to Improve Patient Care. A Procedural Framework for the Conduct of Comparative Clinical Effectiveness Research. November 2010. www.improvepatientcare.org/sites/default/files/CER_Procedure-PIPC_Whitepaper.pdf (108) 
text, which includes a requirement for the process to invite input from a variety of interested parties $(111,112)$. In addition, the essence of stakeholder participation was highlighted in the report's special recommendation that the AHRQ, should involve a broad spectrum of interested parties (112). Further, Sibbald et al (113) described a conceptual framework for priority-setting in health technology assessments, offering stakeholder engagement as a central characteristic. They also noted the need for a genuine commitment by organizations in engaging stakeholders through partnership and employment, as well as the connection between engagement and stakeholder satisfaction with their level of involvement.

The AHRQ has taken steps to implement the recommendations for broad stakeholder participation by establishing a stakeholder advisory group that includes representatives from patients, providers, manufacturers, and private payers. Even though this group does not hold public meetings, it does provide a forum for stakeholder views to be expressed. In addition, using funds provided under the ARRA, the AHRQ is setting up a community forum as a mechanism to engage members of the public in discussions related to CER (108).

The stakeholder participation was also emphasized as an essential component of any process in public comments during the ARRA implementation. The IOM committee on CER priorities, the National Health Council, noted that the ARRA offered "few safeguards" to insure a patient-focus or the inclusion of patients as stakeholders in the governance and decisions-making process (114).

The PCORI's main mechanism for stakeholder participation is through its oversight and/or advisory bodies, only one of which, the Board of Governors, deals explicitly with priority setting. The Government Accountability Office announced the appointments to the 21-member board in September 2010. However, the literature emphasizing the importance of stakeholder engagement as well as the concerns that arose during the ARRA implementation suggests that a more robust engagement mechanism than the Board of Governors may be necessary (108).

The CER provisions of the ACA are unique in the requirements they create for full and active stakeholder participation in both the leadership and the operations of the PCORI. While stakeholder engagement is an important and valuable characteristic of existing HHS programs for CER, it does not have the same central role that is provided by the ACA (111).
It appears that the PCORI program under the ACA is approaching the issue with broad stakeholder participation, however, the stakeholder composition itself appears to be suspect. The IOM and others $(11,13,23)$ are essentially silent on the constitution of the stakeholder groups and total control of the administration. However, the white paper on a National Strategy for CER Dissemination by National Network for Health Innovation (NEHI) (13) does recommend that national medical societies and patient groups are crucial as potential partners going forward. The group consists of 4 representatives of physicians with at least one surgeon without indication whether these are practicing physicians. The composition also provides significant influence for private payors with 3 representatives, 3 members representing pharmaceutical devices, etc., and 3 patient representatives. Consequently, either it will be difficult to make decisions or it will be impossible to reach consensus even if it is not evidence-based.

Table 5 illustrates the composition of the PCORI Board of Governors, and Table 6 illustrates the composition of the PCORI Methodology Committee. Further evaluation of the composition of the Board of Governors illustrates the lack of specialty representation. The lack of physician dominance essentially follows the principle that stakeholders are not physician scientists $(115,116)$. Further, many of the stakeholders have substantial conflicts of interest.

The importance of the methodology committee is that it sets the tone. After the methodology is assigned and reviews are performed, no one pays attention to the methodology and generally public comments are not taken into consideration.

By definition, successful dissemination of CER evidence will require collaboration. Even the highly decentralized nature of evidence dissemination, collaboration, and consensus building will be critical even when CER produces findings that seem to be clear and unambiguous. However IOM is recommending a centralized process. In general, stakeholder groups that are not part of a consensus-building process are less likely to become active advocates for the dissemination of guidelines or other evidence-based aids to decisionmaking or may in fact become active opponents of guidelines (13).

The controversial 2009 United States Preventive Services Task Force (USPSTF) recommendation on mammography screenings is a case in point $(67,68,117-120)$. It is unclear whether the task force's recommendations on mammography screening would have been better 
Table 5. Composition of Board of Governors of PCORI.

\begin{tabular}{|c|c|}
\hline \multicolumn{2}{|l|}{ MEMBERS OF BOARD } \\
\hline Debra Barksdale, $\mathrm{PhD}, \mathrm{RN}$ & $\begin{array}{l}\text { Associate Professor at the University of North Carolina (UNC) at Chapel Hill School of Nursing in } \\
\text { Chapel Hill, NC. }\end{array}$ \\
\hline Kerry Barnett, JD & $\begin{array}{l}\text { Group Executive Vice President, Corporate Services, Chief Legal Officer, and Ethics and Compliance } \\
\text { Officer for The Regence Group. }\end{array}$ \\
\hline Lawrence Becker & Director of Strategic Partnerships and Alliances for Xerox Corporation in Rochester, NY. \\
\hline Carolyn Clancy & Director of the Agency for Healthcare Research and Quality (AHRQ). \\
\hline Francis Collins & Served as the Director of the National Institutes of Health (NIH). \\
\hline Allen Douma, MD & Chief Executive Officer of Empower, LLC, in Ashland, OR. \\
\hline Arnold Epstein, MD & $\begin{array}{l}\text { John H. Foster Professor and Chair of the Department of Health Policy and Management at Harvard } \\
\text { University School of Public Health in Boston, MA, and is a practicing internist in the Department of } \\
\text { Medicine at the Brigham and Women's Hospital. }\end{array}$ \\
\hline Christine Goertz, DC, PhD & $\begin{array}{l}\text { Vice Chancellor for Research and Health Policy at Palmer College of Chiropractic and Palmer Center for } \\
\text { Chiropractic Research in Davenport, IA. }\end{array}$ \\
\hline Leah Hole-Curry, JD & $\begin{array}{l}\text { Program Director for the Health Technology Assessment (HTA) program of the Washington State } \\
\text { Health Care Authority in Olympia, WA. }\end{array}$ \\
\hline Gail Hunt & President and CEO of the National Alliance for Caregiving. \\
\hline Robert Jesse, $\mathrm{MD}, \mathrm{PhD}$ & Principal Deputy Under Secretary for Health, Department of Veterans Affairs in Washington, DC. \\
\hline Harlan Krumholz, MD & $\begin{array}{l}\text { Harold H. Hines, Jr. Professor of Medicine and Epidemiology and Public Health at Yale University School } \\
\text { of Medicine in New Haven, CT, and is a practicing cardiologist. }\end{array}$ \\
\hline Richard E. Kuntz, MD & $\begin{array}{l}\text { Senior Vice President and Chief Scientific, Clinical, and Regulatory Officer of Medtronic, Inc. in Min- } \\
\text { neapolis, MN. }\end{array}$ \\
\hline Sharon Levine, MD & $\begin{array}{l}\text { Associate Executive Director for The Permanente Medical Group of Northern California; in Oakland, } \\
\text { CA, within Kaiser Permanente's integrated delivery system. }\end{array}$ \\
\hline Freda Lewis-Hall, MD & Executive Vice President and Chief Medical Officer for Pfizer Inc. \\
\hline Steven Lipstein, MHA & President and Chief Executive Officer of BJC HealthCare in St. Louis, MO. \\
\hline Grayson Norquist, MD, MSPH & $\begin{array}{l}\text { Professor and Chairman, Department of Psychiatry and Human Behavior, University of Mississippi } \\
\text { Medical Center in Jackson, MS. }\end{array}$ \\
\hline Ellen Sigal, PhD & Chair and founder of Friends of Cancer Research in Washington, DC. \\
\hline Eugene Washington, MD, MSc & $\begin{array}{l}\text { Vice Chancellor of UCLA Health Sciences and Dean of the David Geffen School of Medicine at the } \\
\text { University of California Los Angeles in Los Angeles, CA. }\end{array}$ \\
\hline Harlan Weisman, MD & $\begin{array}{l}\text { Chief Science and Technology Officer, Medical Devices and Diagnostics, for Johnson \& Johnson in New } \\
\text { Brunswick, NJ. }\end{array}$ \\
\hline Robert Zwolak, MD, PhD & $\begin{array}{l}\text { Vascular surgeon at Dartmouth-Hitchcock Medical Center in Lebanon, NH, and professor of surgery } \\
\text { at the Dartmouth Medical School. He is also Chief of Surgery at the Veterans Administration Medical } \\
\text { Center in White River Junction, VT, and director of the Non-invasive Vascular Laboratory. }\end{array}$ \\
\hline
\end{tabular}

accepted if clinicians and other patient groups had been involved earlier. Their lack of involvement in the process clearly helped to fuel opposition to the recommendations. Consequently, the USPSTF's mission and operating procedures, previously held up as a model for other organizations by proclamation of methodologists and centralists, were thrown into serious dispute (68, 117-125).

Thus, national medical societies and patient groups could be potential and crucial partners for the PCORI. Many national organizations operate programs to identify and disseminate standards of practice; however, it has been alleged that few have specifically focused on the development of mechanisms to build rapid consensus and expedite the use of good evidence. This may be a disingenuous and self-serving statement by the methodologists, administration and supporters of the bureaucracy. Further, they also claim that limited fund- 
Table 6. Compositions of Methodology Committee of PCORI.

\begin{tabular}{|c|c|}
\hline \multicolumn{2}{|l|}{ MEMBERS OF BOARD } \\
\hline Naomi Aronson, $\mathrm{PhD}$ & Executive Director of the Blue Cross and Blue Shield Association Technology Evaluation Center. \\
\hline Ethan Basch, MD, MSc & $\begin{array}{l}\text { Practicing medical oncologist and health services researcher at Memorial Sloan-Kettering Cancer } \\
\text { Center, with appointments in the Department of Medicine and in the Department of Epidemiology and } \\
\text { Biostatistics. }\end{array}$ \\
\hline Alfred Berg, MD, MPH & Professor in the Department of Family Medicine at the University of Washington in Seattle. \\
\hline David Flum, MD, MPH & $\begin{array}{l}\text { Professor in the Department of Surgery and Adjunct Professor in Health Services and Pharmacy at the } \\
\text { University of Washington (UW) Schools of Medicine, Public Health and Pharmacy. Co-director of the } \\
\text { the UW Centers for Comparative and Health Systems Effectiveness Alliance and directs UW's Surgical } \\
\text { Outcomes Research Center. Director of Surgical Care and Outcomes Assessment Program. }\end{array}$ \\
\hline $\begin{array}{l}\text { Sherine Gabriel, MD, MSc } \\
\text { (Chair) }\end{array}$ & $\begin{array}{l}\text { Professor of Medicine and of Epidemiology and the William J. and Charles H. Mayo Professor at Mayo } \\
\text { Clinic. }\end{array}$ \\
\hline Steven Goodman, MD, PhD & $\begin{array}{l}\text { Professor of Oncology, Pediatrics, Epidemiology and Biostatistics, Johns Hopkins School of Medicine } \\
\text { and Bloomberg School of Public Health. }\end{array}$ \\
\hline Mark Helfand, MD, MS, MPH & $\begin{array}{l}\text { Professor of Medicine and Professor of Medical Informatics and Clinical Epidemiology at the Oregon } \\
\text { Health \& Science University. }\end{array}$ \\
\hline John Ioannidis, MD, DSc & $\begin{array}{l}\text { C.F. Rehnborg Chair in Disease Prevention, Professor of Medicine, Professor of Health Research and } \\
\text { Policy, and Director of the Stanford Prevention Research Center at Stanford University School of Medi- } \\
\text { cine and Professor of Statistics (by courtesy) at Stanford University School of Humanities and Sciences. }\end{array}$ \\
\hline Michael Lauer, MD & Director of the Division of Cardiovascular Sciences at the National Heart, Lung, and Blood Institute. \\
\hline David Meltzer, MD, PhD & $\begin{array}{l}\text { Chief of the Section of Hospital Medicine, Director of the Center for Health and the Social Sciences } \\
\text { (CHeSS), Chair of the Committee on Clinical and Translational Science, and Associate Professor in the } \\
\text { Department of Medicine, Department of Economics and the Harris School of Public Policy Studies at } \\
\text { the University of Chicago. }\end{array}$ \\
\hline Brian Mittman, $\mathrm{PhD}$ & $\begin{array}{l}\text { Director, VA Center for Implementation Practice and Research Support, Department of Veterans Af- } \\
\text { fairs Greater Los Angeles Healthcare System and Senior Social Scientist at the VA/UCLA/RAND Center } \\
\text { for the Study of Healthcare Provider Behavior. }\end{array}$ \\
\hline Robin Newhouse, PhD, RN & $\begin{array}{l}\text { Assistant Dean for the Doctor of Nursing Practice Program and Associate Professor, Organizational } \\
\text { Systems and Adult Health, University of Maryland School of Nursing. }\end{array}$ \\
\hline $\begin{array}{l}\text { Sharon-Lise Normand, MSc, PhD } \\
\text { (Vice Chair) }\end{array}$ & $\begin{array}{l}\text { Professor of Health Care Policy (Biostatistics) in the Department of Health Care Policy at Harvard } \\
\text { Medical School and Professor in the Department of Biostatistics at the Harvard School of Public Health. }\end{array}$ \\
\hline Sebastian Schneeweiss, MD, DSc & $\begin{array}{l}\text { Associate Professor of Medicine and Epidemiology at Harvard Medical School and Vice Chief of the } \\
\text { Division of Pharmacoepidemiology and Pharmacoeconomics at the Brigham and Women's Hospital. } \\
\text { Principal Investigator of the BWH DEcIDE Research Center on Comparative Effectiveness Research } \\
\text { and the DEcIDE Methods Center both funded by AHRQ and PI of the Harvard-Brigham Drug Safety } \\
\text { Research Center funded by FDA/CDER. }\end{array}$ \\
\hline Jean Slutsky, PA, MSPH & $\begin{array}{l}\text { Director of the Center for Outcomes and Evidence (COE), Agency for Healthcare Research and Quality } \\
\text { (AHRQ) of the U.S. Department of Health and Human Services. }\end{array}$ \\
\hline Mary Tinetti, MD & $\begin{array}{l}\text { Gladdys Phillips Crofoot Professor of Medicine, Epidemiology, and Public Health in the Division of } \\
\text { Geriatrics at Yale University School of Medicine. }\end{array}$ \\
\hline Clyde Yancy, MD, MSc & $\begin{array}{l}\text { Chief, Cardiology, Northwestern University Feinberg School of Medicine and Associate Director, The } \\
\text { Bluhm Cardiovascular Institute at Northwestern Memorial Hospital. }\end{array}$ \\
\hline
\end{tabular}

ing and the complexity of bringing experts together can constrain the consensus-building process, as evidenced by the NIH Consensus Development Program, which releases no more than 3 or 4 consensus statements per year (126). However, there is no proof for such allegations and there is no evidence that anything developed by NIH Consensus Development Program has been methodologically sound and has improved either health care, or access to the patients, or even costs.

In contrast, even small organizations such as American Society of Interventional Pain Physicians (ASIPP) have developed guidelines without major conflicts of 
interest or funding. These guidelines have not been accepted by the rule makers. Efforts to clarify the lack of acceptance have only generatedroutine and inappropriate explanations $(30-41,71-75,79-81,115,116,127-$ 180). Further, the effectiveness of the guidelines developed by AAHCPR and the present effectiveness health care programs is open to question. The guideline development continues to cost taxpayers millions of dollars per guideline, yet the guidelines are neither understandable nor useful for clinical application. The shortcoming of these guideliines seems to arise from the development process, as most of these are prepared by methodologists without understanding the clinical aspects and by physicians who function as methodologists either out of clinical practice, having only a token practice or not aware of the clinical practice in that particular technology they are evaluating.

EBM and CER is based on not only methodologic quality assessment of studies, but, also the understanding of the clinical nature of the technique, procedure, or intervention being evaluated.

Overall, as in the case of the PCORI, stakeholder groups may disagree on the implications of evidence, even when the evidence seems to be clear. Further, many of the groups which are contracted outside the agency also possess substantial conflicts of interest, as the income source even in non-profit organization can be unclear and as representative from various insurance and manufacturer stakeholders may have conflicting loyalties. Recently, the American College of Chest Physicians and the American Academy of Orthopedic Surgeons took markedly different positions on the outcomes to be used in defining the efficacy of measures to prevent thromboembolism during hip and knee surgery (181). The same philosophy applies to interventional techniques and surgical interventions. There is always disagreement between interventional pain physicians and surgeons with contradictory opinions for both.

The conflict in guideline preparation dissemination, transparency, and openness has been well described along with intricacies, complications, and difficulties in the systematic assessment of evidence $(142,148,182$ 206). There is over representation of multiple organizations and some institutions (182). It has been stated that financial relationships with pharmaceutical, medical device, and biotechnology companies may create conflicts of interest and a risk of undue influence on $j$ entities that sponsor the development of clinical practice guidelines or systematic reviews, and for the individuals who participate in their development (182-206).
In addition to the financial relationship with industry, other potential sources of bias in the development of clinical practice guidelines include professional affiliations and practice specialization, reimbursement incentives, intellectual preconceptions and previously stated positions, and the desire for recognition and career advancement. However, the conflicts of interest of academic positions, the research, and the original source of funding even if it appears not related to the pharmaceutical industry or device manufacturers, and the basic income derived from non-profit organizations is not well described $(198,207-211)$. Numerous organizations with purposes and objectives of advancing health care mostly are associated with one or the other view and consist of financial conflicts of interest or IOM publication on conflict of interest in medical research education and practice (212). The sections on conflicts of interest and development of clinical practice guidelines (212) describe extensively how it is difficult for organizations to fund. They also show that multiple organizations provide funding from their general revenues. ASIPP also funds their guidelines from general revenues. No one is paid except for travel, accommodations, etc. when special meetings are held. Ironically, the IOM quotes personal communication by Roger Chou stating that smaller professional societies that have sought to fund clinical guidelines development and systematic reviews without industry support have found it difficult to do so. They suggest that professional societies nominate topics for AHRQ-supported systematic reviews. The same publication also reveals that each systematic review may cost approximately $\$ 200,000$. These statements themselves illustrate a conflicts of interest because Chou did not divulge the receipt of approximately $\$ 1.2$ million from APS which received its funding from drug manufacturers, resulting in opinions which were favorable to opioids without evidence, and the rejection of any reasonable evidence for interventional techniques and the denial of evidence for any and all interventional techniques in managing low back pain $(132,213)$. The influence of industry on the development of opioid guidelines is also illustrated in the activities of the Wisconsin Pain Policy Studies Group which provided model guidelines to the Federation of Medical Boards, were eventually followed by many of the medical boards, promoting opioid use while on the surface looking to control opioid abuse $(200,214)$. Further, the same evidence synthesis was utilized by Spectrum Research, without consideration of peer review comments, which also provided remuneration to Chou 
for his services, as the only physician on the evidence synthesis committee for interventional techniques for Spectrum Research. Thus, we cannot consider that publicly funded guidelines within the United States or England are without bias and are accurate.

Thus, the PCORI, instead of restricting and doing business behind closed doors, should challenge all the communities in medicine to rally around a common approach to evidence synthesis, consensus building, and the dissemination of appropriate guidelines with proper stakeholder involvement.

\subsection{Transparency}

The process must be transparent and open. It's a key element throughout the process. The absence of this element may limit the value of each of the subsequent elements.

If openness and transparency are not present, any process viewed by decision-makers as fair and objective may be perceived very differently by patients and providers and by the public at large. This important point was noted in the IOM's 1992 report, "Setting Priorities for Health Technologies Assessment: A Model Process," which noted among its guiding principles that the process "must be - and must appear to be - objective, open, and fair." Further, the IOM observed that the process "must present the logic of the process clearly and carefully to others" (112).

Daniels and Sabin (215) have offered that a fair process "will involve transparency about the grounds for decisions; appeals to rationales that all can accept as relevant to meeting health needs fairly; and procedures for revising decisions in light of challenges to them." When combined, the authors suggest that these components create "accountability for reasonableness," which allows for the education of stakeholders on the material included in deliberations and aligns decisionmaking "to broader, more fundamental democratic deliberative processes" (216). Finally, Sibbald et al (113) suggest that transparency may contribute to the overall success of a program through positive media coverage; peer emulation; or changes in policy, legislation, or practice.

Transparency is an important issue which is lacking not only in the PCORI, but at many levels of health care. When it does exist, it is limited to following the rules and regulations and publishing the results without any input from the public as the materials submitted by the public are not considered. The PCORI should publish transparently all the stakeholders involved and their conflicts of interest not by illustrating their present positions, but by providing the financial information in great detail. The PCORI also will be best to provide transparency in the gaps of knowledge and their inability to assimilate and discuss the deficiencies openly. Further, Congress along with the President, should not only receive a nominal report from the board, but these reports must be made available to the public including the details of the institute's research methodology priorities, activities, and conflicts of interest.

\subsection{Public Participation}

Stakeholder involvement, transparency, public participation, and open decision-making all go hand-inhand. Public participation should never be a nominal or a philosophical approach, but ishould be substantive with consideration of all aspects, including the ability to admit the shortcomings of the commission. In the past, the public forums and listening sessions were offered by the IOM and the Federal Coordinating Council for CER. Thee PCORI has a 45 to 60 day comment period for the public to respond to research priorities, and also requires the Institute to provide additional input opportunities (e.g., through a website). This approach still might not ensure meaningful and comprehensive input, and be considered deficient. Coulter and Ham (217) suggested that the need for an unbiased and systematic approach for encouraging patient and public participation in the process is "a crucial step toward reducing the democratic deficit in health-care decision making."

Sibbald et al (113) recommended that decisionmakers adopt multiple techniques to solicit stakeholder feedback, including roundtables, open forums, and administrative meetings. Patient and consumer groups have also noted the importance of multiple opportunities for stakeholder input, chiefly among patients and clinicians. The National Working Group on EvidenceBased Health Care issued a policy paper in August 2008 that called for patient and consumer engagement in defining a CER research agenda through the creation of a separate patient/consumer advisory body whose purpose would be to advise the organization throughout the research process (218). Given these perspectives, the PCORI and other CER organizations should strive to implement and ensure meaningful opportunities for public guidance in priority setting. Instead, not only the PCORI, but the IOM, AHRQ, their contractors, and other organizations even if not for profit failed to take into consideration public comments which at times may be crucial in the decision-making process. The members of 
the committees at various levels do not have the time or resources to evaluate or even read the public comments, thus there should be an open mechanism for public comments to be taken into consideration, which has been done to a great extent positively, by the CMS in preparing various payment schedules (219-221). Consequently, the decision-makers must incorporate the input they receive in a systematic manner.

\subsection{Open Decision-Making}

Transparency and open decision-making are 2 peas in a pod. However, there are multiple issues to be considered in open decision-making. The decision-making must be open not only by vote of the governors, but also the ad hoc committees. CER decisions to date have been made by federal officials, with no opportunity for the public to witness how important determinations are made, how research priorities are set, how funding decisions are made, how research gaps and methodological challenges are considered and addressed, and how non-public meetings with particular stakeholders impact decisions. Finally, the cost of any of these activities is never provided to the public, or for that matter to Congress. Further, the involvement of private contractors must be open and transparent showing their own conflicts of interest. Consequently, a more open decision-making process might enhance the credibility of these determinations and increase the acceptability.

Open decision-making also should address the issues with regards to the handling of situations where members disagree on important matters. Given the broad representation of stakeholders on the board, it is likely that disagreements will occur on matters like the methodological approaches taken in specific research efforts and the interpretation of research findings.

Open decision-making is essential specifically for the methodological process. The expert advisory panel, including patient subgroups, should provide advice on research designs and protocols, and it requires that a methodologic committee develop standards for conducting CER that account for and evaluate patient subpopulations. However, the deficiencies at the present time exist even in understanding randomized control trials, their subgroups, and placebo control and nocebo hyperalgesia. Further, the attention must be focused on effectiveness rather than efficacy, and, as much as possible, away from strict adherence to academic centers and placebo controlled randomized double-blind trials, unless the institute is focused on eliminating the entire medicine.

Further, the institute must follow the same rules and regulations for all interventions considered in the research rather than continue to change for each regulation based on their own interpretations and following the recommendations of the methodology committee only when it is convenient.

\subsection{Impact OF PCORI ANd CER}

The $\mathrm{CBO}$ report states that to affect medical treatment and reduce health care spending, the results of comparative effectiveness analysis would ultimately have to change the behavior of doctors and patients (103). Further, for any large-scale changes to occur, CER would have to generate new findings for a substantial number of medical conditions, which may take many years. To have the maximum effect on behavior, these findings would then have to be incorporated into the incentives for providers and patients, a process of adjustment that might also take time.

Health policy-makers and health care advisors foresee that there is a potential for savings on health care; however, predicting the impact CER could have on health care spending is difficult. In essence, research could show some of the denied treatments are effective; then there would be a public outcry. CER could also cause spending to increase on treatments already considered effective, but not used as extensively as recommended protocols indicate. Even then, new research on comparative effectiveness seems unlikely to increase the use of services that are already deemed effective. But, as shown in Fig. 1, it appears quite certain that it will decrease the utilization and the cost (222). The 10-year impact of CER has been shown to illustrate approximately $\$ 368$ billion in systemwide savings.

The PCORI in essence may provide the support for private and public payors to implement cost-effective measures based on CER, no matter how deficient it may be.

Consequently, private insurers may not cover drugs, devices, or procedures that were found to be less cost effective. Alternatively, insurers could require enrollees to pay some or all of the additional costs of more expensive treatments that were shown to be less effective or less cost-effective, also known as value-based insurance design.

\subsection{The Impact of Well Established Comparative Effectiveness Research's Programs}

NICE is the best known example of an agency that assesses medical treatments and is most praised by policy-makers and promoters of national health care and 
criticized by many sectors of public groups and physician groups in the United States. NICE has published appraisals of over 100 specific technologies, guidance on the use of over 200 medical procedures, and about 60 sets of treatment guidelines (223). If NICE approves a drug, device, or procedure, it must be covered by the NHS, but local health authorities make coverage decisions about treatments that NICE has not yet evaluated. With a staff of about 200 and an annual budget of over $\$ 60$ million, NICE does not fund new clinical trials or other forms of primary data collection. Instead, it commissions systematic reviews of existing research on clinical effectiveness and combines those findings with models of cost-effectiveness. Clinical trials are funded by the British Ministry of Health, but data on total spending in the United Kingdom for research on comparative effectiveness are difficult to come by. The opponents of the British health care system and NICE criticize that NHS health care is rationed through long waiting lists and, in some cases, omission of various treatments. It has been stated that NICE at its heart is a center for health technology evaluation that issues formal guidance on the use of new and existing medicines based on rigid and proscriptive "economic" and clinical formulas $(7,78)$. Even though the NHS is obliged to adhere to NICE's pronouncements, criticism of NICE has been ceaseless, particularly from various patient organizations. Consequently, NICE is considered a controversial body.

The criteria by which NICE makes its decisions have been kept largely secret from the public (78). The evidence used by NICE has been systematically disputed by clinical experts who are more concerned with patient welfare than with vote-seeking, but the institute has also come under fire for not involving doctors who are active on the frontline of medicine (224). In the past year or so the NHS and NICE have been undergoing atransformation (225-236). The criticism is analogous to the criticism which was faced in the United States by the AHRQ's panel on mammography recommendations $(67,68,117-125,237,238)$.

Nicholas Timmons, a public policy editor of the Financial Times in London and vising professor and a senior associate of Nuffield, in an article in December of 2010, wrote that the United States is not alone in undertaking health system reform amid financial uncertainty. A new British government prepares for a major renovation of the NHS on which the United States is modeling upon. This is the system the PCORI is depending on. There have been numerous complaints about NICE and its dealings and in NHS in general $(225,236)$. It has been described that NICE has managed to suppress costs at its methodology, and ignores choice and individual predilection. According to Berwick, the CMS administrator, "the decision is not whether or not we will ration care - the decision is whether we will ration with our eyes open" (21). Despite the claims that health care is poor in the United States, a 5-year survival rate for breast cancer and prostate cancer, are significantly

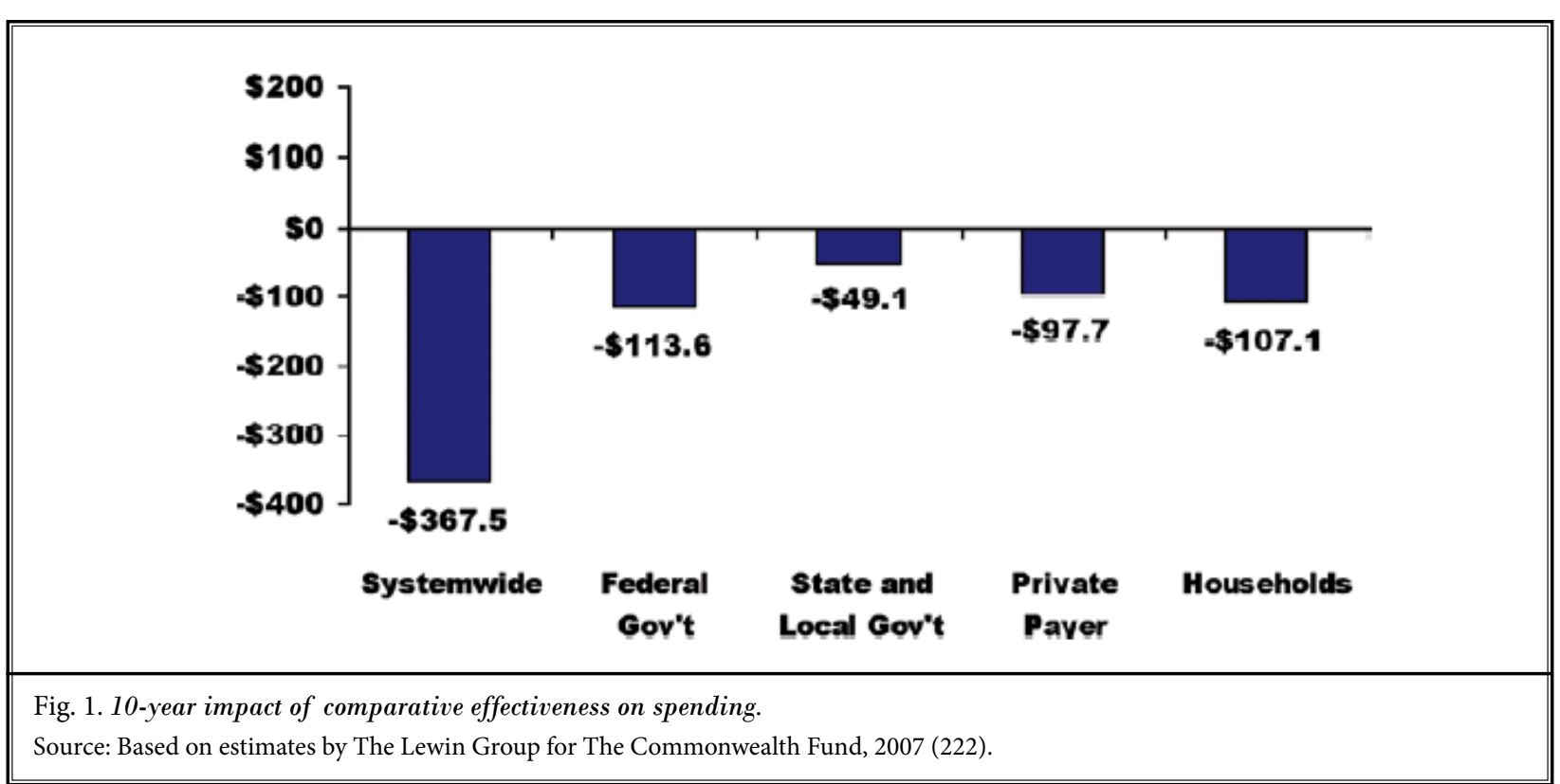


higher than that of England. In the United States, the survival rates for breast cancer and prostate cancer are $83.9 \%$ and $91.9 \%$ respectively, compared to $69.7 \%$ and $51.1 \%$ in England (239). Since 2000, when the labor prime minister Tony Blair made a pledge to get Britain's comparatively low health spending up closer to the European average, NHS expenditures have been rising $6 \%$ to $7 \%$ a year in real terms. Now, the years of spectacular growth in the NHS budget are grinding to a halt. The NHS faces a budget freee in real terms for the next 4 years - likely to be the most for the system since the 1950s. Britain is facing the same problems as the United States and the system needs to produce up to $\$ 20$ billion a year (US $\$ 32$ billion) in savings, even as it struggles to cope with an aging population, the advance of medical technology, and other pressures faced by all health systems world wide. One of the important aspects of NICE is that they are proposing that the administrative costs of managing the NHS be slashed by $45 \%$. Under the NHS, primary care physicians are not employed by the government, but rather function as independent contractors, whereas specialists are employed by one of the many publicly owned hospitals. A patient always has to be refereed to a specialist by the primary care practitioner. However, over the years more independence has been provided to the hospitals and the specialists. In the new proposed system, family doctors will have much more say than they had in the previous years. However at the moment, these proposals are a statement of the government's intent and have not been formally translated into legislation. However, NICE along with the NHS is facing a makeover from what we are attempting to adapt and what we have known.

Based on the controversy of NICE, as generated on quality of life issues with new health care technologies and drugs, the PCORI may not use the cost at least for now. One of the conservative health ministers said that NICE's assessments of whether or not an intervention was cost-effective will become somewhat redundant, due to the changes coming. Thus, as far as NICE is concerned, the only thing clear at this point about NICE's future is that nothing is clear. Unfortunately we can't say the same about the PCORI.

In fact, it would be very tempting for federal regulators to exploit CER to ration care. This would be implemented by financially punishing physicians prescribing the "less effective" interventions with lower reimbursements or refusing to pay for them outright. Thus, if the government is prepared to go down this route, it could apply tremendous pressure on physicians to coerce them to practice to its liking. Recently, Pearson and Bach (240) advocated for such a regimen where reimbursement would be tied to the comparative clinical effectiveness of a product. However, this would be a stark deviation from Medicare's current reasonable and necessary "bench mark." However, private insurers do not have to follow any of these recommendations, and thus are already implementing findings of poorly performed flawed CER and many aspects of the ACA which is awaiting to be implemented in 2014. Further, it should be noted that the ACA explicitly says it should not be construed as preventing the secretary from using evidence or findings from such comparative clinical effectiveness research in determining coverage, reimbursement, or incentive programs (2-4). Thus, the PCO$\mathrm{RI}$ will recommend treatment regimens for the standard patient. These recommendations, coupled with reimbursement changes, could easily pave the way for government dictating to patients the medicines, tests, procedures, and medical interventions they can and cannot have, irrespective of willingness to pay for an individual preference. This one-size-fits-all approach could replace the professional judgement of the physician actually examining and talking to the patient with rules set by regulators in Washington. Consequently, such an approach may control rising costs, but would not "bend the cost curve," but arbitrarily would flatten it (7).

Thus, due to multiple uncertainties and differences even in established programs, American physicians consider comparative effectiveness as problematic. Further, the application of CER is much more primitive with surgical techniques, interventional procedures, and multiple devices. Finally, the unlimited powers granted to the DHHS and their organizations controlled by the administration rather than Congress remain a major issue.

\subsection{The Present State of Cer in the U.S.}

In recent publications it was illustrated that adverse events in hospitals based on IOM standards do not accurately measure them (48). It is well known that improving patient safety continues to be a priority for both policy makers and health care providers. As a result, during the 10 years since the publication of the IOM's landmark report, To Err Is Human: Building a Safer Health System, there have been numerous initiatives to improve the safety of patient care in the United States (49-52). Since then, several studies have reported on the often 
resource-intensive interventions intended to improve the safety and reliability of care (50-52). Many studies have attempted to evaluate the safety of US health care overall. Some emphasize great progress, and others highlight how much more work is to be done. However, none of these studies have taken into consideration the cost and cost-benefit ratio of these interventions. In a study of hospitals in North Carolina showed a high rate of adverse events that has not changed over time, despite notable efforts in the state to improve the safety of in-patient care, at ever-increasing costs (53-55). Clauson et al (48) have described that the key challenge has been agreeing on a yardstick for measuring the safety of care in hospitals (56), despite multiple tools and the ever-expanding costs with regulations not only from government agencies, but also from accrediting bodies $(241,242)$. An IOM-sponsored review noted that while entry reporting systems missed many significant adverse events, and it called for the development of other methods for measuring patient safety (243). Consequently, multiple instruments have been developed including automated reviews. Most of them, even the ones that applied by the Harvard Medical Practice Study, have been shown as either lacking sensitivity, too expensive, or extremely labor intensive without providing appropriate data (57-59,244-246). Yet, another tool was developed by the Institute for Health Care Improvement, namely the Global Trigger Tool (60). Utilizing this sensitive tool after many years and expenses illustrated not only that all the measures have not improved the care by reducing the adverse events in hospitals but, adverse events in hospitals may be 10 times greater than previously measured (48), with overall adverse events occurring in one-third of hospital admissions. This spectacular conclusion was based on a retrospective review of 795 patient records. Adverse events occurred in $33.2 \%$ of hospital admissions, some patients experiencing more than one adverse event, the overall rate was 49 events per 100 admissions. Patients who experienced adverse events were older and had a higher mortality, longer hospital stay, and a higher case-mix index, which measures the characteristics of patients treated based on resource use and intensity of care, than patients without an adverse event. However, what is ignored is the conflict of interest of these authors who are all employed by the organization which developed the tool and will probably provide at a modest cost.

The second case in point regards to the infection control and the role of CER. A commentary about infection prevention in CER (61) described that health care-acquired infections, particularly those due to antimicrobial-resistant bacteria, have received significant attention in recent years. In fact, CMS and other agencies have established rigid controls on many of the aspects of infection control even including ambulatory and in-office procedures that are simple injections, not requiring a skin incision $(62-67,247)$. The institution of strict and extended infection control programs cost the federal government millions of dollars and cost hundreds of thousands of dollars for each practice and hospital to implement. These are based on spotty evidence, without appropriate epidemiological surveys, resulting in regulations without any evidence. This may have created many incentives and jobs for personnel for inspection purposes and to implement enhanced infection control measures, and for interested parties, it has become a cottage industry.

In fact, as of 2011, it has been shown that an evidence-based intervention bundle did not reduce surgical site infections (248). They concluded that the bundling of interventions, even when the constituent interventions have been individually tested, does not have a predictable effect on outcome. Thus, they recommend yet another formal testing of bundled approaches prior to implementation. In a commentary (249), the overall rate of surgical site infection was $45 \%$ in the extended arm of the study and $25 \%$ in the standard arm. Most of the increased number of infections in the extended arm were superficial incisional surgical site infections. Kim (249) commented that improvements in surgical care can take several forms: major advances that revolutionize the field; incremental improvements; and seemingly better practices that are later abandoned. Even though patients treated with the extended bundle faired significantly worse than patients not receiving the bundle, having a higher rate of surgical site infections, Kim (249) commented that although a neutral result from this trial might be understandable, an adverse effect of these combined interventions is counterintuitive because individually each of these interventions has been thought to reduce wound infections. For example, the Institute for Health Care Improvement has recommended bundles of interventions to prevent central line infections and ventilator-associated pneumonia (250). This is the same institute that developed the Global Trigger Tool as illustrated above (48). In another study of intervention to reduce transmission of resistant bacteria in intensive care (251), expanded barrier precautions or interventions as compared with the existing practice (control) 
showed the interventions to be ineffective in reducing the transmission of methicillin-resistant staphylococcus aureus (MRSA) and vancomycin-resistant enterococcus (VRE).

Along similar lines, potential flaws of randomized trials of vitamin supplements have been described (252). The extensive research on vitamin $D$ even then it is considered not ready for prime time. Further, dietary reference intakes for vitamin $D$ established by the IOM, charging with determining the population needs for vitamin D in North America, fail to play any roles in outcomes beyond bone health, including, cancer, cardiovascular disease, diabetes, and autoimmune disorders (253). The researchers failed to take into consideration their own results of publications which provide contradictory results (254). In a best-evidence review of diagnostic procedures for neck and low back pain Rubinstein and van Tulder (254) provided strong evidence for certain diagnostic interventions; however, these were never taken into consideration. Finally, the broadened scope of nursing practice and empowering them to do multiple procedures is not based on evidence-based practice, but based on legislation rather than education (255). The skepticism is based on previous experiences and regulations with increasing preventable errors, infection rates, which have not been reduced by increasing regulations and in fact increasing the costs and eventually may reduce quality and access to care. Further, numerous challenges have been described with CER and its application (256-262).

Further, all concerned with CER may fall onto rigid efficacy studies with randomized control trial and its misinterpretation of active control trials. Based on flawed evidence, commentators in the New England Journal of Medicine (79) described that without randomized trials, ineffective and costly treatments with risks and complications would continue to be administered largely because the alternative treatments are disappointing. They also considered that CER won't always yield definitive conclusions about therapies effectiveness and individual patients might benefit despite disappointing results in randomized trials. However, such statements and facts are never taken into consideration when making the recommendations. In addition, family planning as a cost-saving preventive health service (263) illustrates that in 2001, an estimated 3.1 million pregnancies were reportedly unwanted or mistimed, and by 45 years of age, nearly half of US women will have had an unintended pregnancy. Authors recommend family planning services, etc. which have been present for several years with numerous entitlement programs which may or may not provide incentives or disincentives, once again illustrating regulatory fixes are always not effective.

\subsection{Impact on Interventional Pain Management}

The major impact on interventional pain management would be a lack of interventional pain management clinicians on panels evaluating interventional techniques for comparative effectiveness and panels making recommendations for coverage or lack thereof. It is a common practice in interventional pain management to perform systematic reviews and prepare guidelines by a host of physicians considered peers and clinicians, even though these physicians are only methodologists, unaware of many of the clinical elements of interventional pain management. The lack of understanding of technical aspects of interventional techniques, placebo analgesia, and nocebo hyperalgesia, and methodological flaws based on conflicts of interest are major drawbacks. Consequently, the validity of any evaluation will be considered invalid or mostly focused on benefits for the guideline preparer $(30-41,72,75,132-138,143-148)$.

\subsection{Interventional Pain Management Under NICE}

Multiple evaluations and publications related to interventional pain management have been published by NICE (264-270). These evaluations essentially confirm the fear and uncertainty of American interventionalists. NICE (264), in conjunction with the National Collaborating Centre for Primary Care (NCC-PC) and Royal College of General Practitioners (RCGP) (265), developed guidelines for early management of persistent non-specific low back pain. However, these have been inappropriately applied for chronic persistent low back pain.

The evidence statement provides that searches were carried out to identify any form of injection for the lower back; however, only data on facet joint, prolotherapy, and intradiscal injections were identified. It was very surprising that such a search criteria should fail to identify numerous treatments, including multiple guidelines and systematic reviews. Consequently, it appears that evidence synthesis is suboptimal with inappropriate application from one evaluation to another, such as from non-specific acute low back pain to chronic persistent specific low back pain. Among the interventional procedures, NICE has provided positive 
evidence for spinal cord stimulation for chronic pain of neuropathic or ischemic origin (271).

\subsection{PCORI and CER in the U.S.}

CER in the United States is confused with EBM. Though both are similar, there are some differences. Further, it is controlled by a few people in the country who are intermingled with the Cochrane Review Group and others in the United Kingdom and other countries. Tragically, they fail to utilize appropriate methodological principles and lack accountability and transparency. Most organizations only discuss the process, never their deficiencies and conflicts of interest, while they discuss the conflicts of interest of others.

Multiple organizations, either for-profit or notfor-profit, are vested in CER. Even though these organizations may appear as not-for-profit, they do have a business to run including payroll and maintenance. Conflicts of interest range from the origin of the funding to the final use. The majority of the funding comes from either manufacturers or insurers with divergent philosophies. The authors regularly fail to disclose their incomes and how they have been derived which creates conflicts of interest. As an example, the Washington State Health Authority System has produced numerous guidelines, some entirely without public input. Their recent spinal injections guidelines were evaluated by Spectrum Research by only one physician. This produced controversial guidelines, without information on the cost and the benefits derived by the company and the participants $(73,76)$. None of the peer review suggestions were taken into consideration, though the analysis was flawed (75). Further, the open-discussion forums were avoided although they finally were heard with substantial restrictions. The final decision by the committee took into consideration only what was presented by Spectrum Research, which was totally flawed and biased and some individual presentations. Understandably, the committee members neither have time nor resources to review the evidence themselves; however, at least they could have reviewed the peer review reports and the reports from others. One of the members of this organization is also on the Board of Governors of the PCORI, even though, this individual's expertise is related to administration.

Numerous divergent guidelines and interpretations with the same evidence yielding different results by different groups have been presented. This has been frequently illustrated by the authors who are consistently negative about interventional pain management.
In fact, reassessment of Chou and Huffman's evaluation (132), illustrates that they have utilized multiple studies inappropriately and have excluded appropriate studies. Also, Chou and Huffman failed to eliminate their bias in their study evaluations.

Further, the integrity assessment showed deep concerns that the APS guidelines $(40,41)$ illustrating significant methodologic failures which raise concerns about transparency, accountability, consistency, and independence due to not only methodology, but conflicts of interest.

Another prime example is American College of Occupational Medicine Practice Guidelines which have been reassessed $(72,137,138)$. It has been concluded taht the ACOEM guidelines on chronic pain and low back pain lack applicability in modern patient care due to the lack of expertise by the developing organization - ACOEM; lack utilization of appropriate and current EBM principles; and lack significant involvement of experts in these techniques, resulting in a lack of clinical relevance. Thus, Manchikanti et al (72) concluded that this may result in reduced medical quality of care; may severely hinder access to appropriate, medically needed and essential medical care; and finally, may increase costs for injured workers, third party payors, and the government by transferring the injured worker into a non-productive disability system. Contrary to ACOEM's conclusions of insufficient evidence for most interventional techniques, the reassessment results showed extensive deficiencies illustrating evidence different from that published in their manuscripts.

In contrast, rigorously performed evidence-based guidelines for interventional techniques by ASIPP (30) with multiple supporting documentation of these guidelines (154-160) and 21 systematic reviews (150,161179,272 ) utilized strength of evidence as assessed by USPSTF criteria using 5 levels of evidence ranging from Level I to III with 3 subcategories in Level II and quality of individual articles, and quality of systematic reviews as described by Cochrane Review and AHRQ criteria $(273,274)$. With adherence to evidence-based principles and strict criteria applying methodology, clinical knowledge, and relevance, these guidelines' conclusions were quite different from ACOEM, ODG, and APS guidelines.

Numerous systematic reviews also have been published in interventional pain management in the U.S. and abroad. Similar to guidelines, the systematic reviews also arrive at different conclusions utilizing the same evidence due to methodological flaws, bias, and lack of clinical knowledge (150-153,161-179,272,275-288). 


\subsection{Conclusion}

The PCORI should not only outline the principles of transparency, independence, stakeholder involvement, but also, nondiscrimination of the evidence. The historic and transformational ACA continues to be profoundly troubling for some and controversial for many. There is lack of understanding in the public about what this law does and its effects. It appears that it will result in insurance for many and coverage for few. Consequently, the national debate over the ACA has raised hurdles to the implementation on dissemination of CER by creating public skepticism over the mission and value of CER, and consequently the PCORI. Supporters believe that the central thrust of the CER mission as outlined in the law is one that should command broad support to improve health care for individual patients by finding more effective ways to treat illness and deliver care. This is promising in the opinion of some, whereas it creates a perfect storm in medicine for others.

The PCORI for the first time, at least on the paper, brings together many stakeholder representatives including patients, consumers, and care-givers, and they will be the decision-makers. However, as with all the government agencies, the PCORI, even though considered as a private organization, suffers the same drawbacks and deficiencies, with the continued involvement of the AHRQ, NIH, and IOM with their well known conflicts of interest and inability to produce any useful accepted CER in the past.
The supporters are starting to promote CER and its mission, that the PCORI must take a visible leadership role and make bold decisions. However, the skeptics and opponents have a different view and are even considering its elimination (263-271).

\section{Acknowledgments}

The authors wish to thank Tom Prigge, MA, for manuscript review, and Tonie $\mathrm{M}$. Hatton and Diane $\mathrm{E}$. Neihoff, transcriptionists, for their assistance in preparation of this manuscript. We would like to thank the editorial board of Pain Physician.

\section{Disclosures}

Author Contributions: Dr. Manchikanti managed the literature searches and wrote the first draft of the manuscript. All other authors provided revision for intellectual content and final approval of the manuscript.

Conflict of Interest Disclosures: All authors have no conflicts of interest to report. None of the authors of the manuscript received any remuneration. Further, the authors have not received any reimbursement or honorarium in any other manner. All the authors are members of the American Society of Interventional Pain Physicians (ASIPP) and practicing interventional pain physicians. Dr. Hirsch is a practicing neuroradiologist.

Funding/Support: There was no external funding in preparation of this manuscript. 


\section{References}

1. Yudkin JS, Richter B, Gale EA. Intensified glucose control in type 2 diabetes - whose agenda? Lancet 2011; 377:12201222.

2. Public Law No: 111-148: H.R. 3590. Patient Protection and Affordable Care Act. March 23, 2010.

3. Manchikanti L, Caraway DL, Parr AT, Fellows B, Hirsch JA. Patient Protection and Affordable Care Act of 2010: Reforming health care reform for the new decade. Pain Physician 2011; 14:E35-E67.

4. Bredesen P. Fresh Medicine: How to Fix Reform and Build a Sustainable Health Care System. Atlantic Monthly Press, New York, 2010.

5. Patient-Centered Outcomes Research Institute. www.pcori.org/

6. Dolinar R. Comparative effectiveness research: Political science, not medical science. Health Care News, May 2011.

7. Fodeman J. The new health law: Bad for doctors, awful for patients. Galen Institute, April 2011.

8. Manchikanti L, Hirsch JA. Obama health care for all Americans: Practical implications. Pain Physician 2009; 12:289-304.

9. Moffit RE. Doctors, patients, and the new Medicare provisions. Heritage Foundation, December 14, 2009. www. heritage.org/Research/Lecture/2010/12/ Doctors-Patients-andthe-New-Medicare-Provisions

10. Capretta JC. The Independent Payment Advisory Board and Health Care Prices Controls. Kaiser Health News, May 6, 2010. www.kaiserhealthnews.org/Columns/2010/May/050610Capretta.aspx

11. Wechsler J. Researchers grapple with CER challenges. Applied Clinical Trials Online November 1, 2010. http://appliedclinicaltrialsonline.find pharma. com/appliedclinicaltrials/article/articleDetail.jsp?id=693547

12. Eden J, Levit L, Berg A, Morton S (eds); Committee on Standards for Systematic Reviews of Comparative Effectiveness Research; Institute of Medicine. Finding What Works in Health Care. Standards for Systematic Reviews. The National Academies Press, Washington, DC, 2011.

13. Hubbard T, Daimyo S, Desai K; New England Healthcare Institute. From Evidence to Practice: A National Strategy for CER Dissemination. February 2011. www.nehi.net/uploads/full_report/cer_ white_paper_final.pdf

14. The Lewin Group Center for Comparative Effectiveness Research Symposium 2010. Responding to the National CER
Agenda: Evolving Data Sources and Analytics. October 12, 2010. http://cdn.lewin. com/Lewin/docs/Lewin\%2oCER\%20 Symposium\%2oWhitepaper\%2oFINAL. pdf

15 Epstein RM, Fiscella K, Lesser CS Stange KC. Why the nation needs a policy push on patient-centered health care. Health Aff (Millwood) 2010; 29:1489-1495.

16. Bonham AC, Solomon MZ. Moving comparative effectiveness research into practice: Implementation science and the role of academic medicine. Health Aff (Millwood) 2010; 29:1901-1905.

17. Garrison LP Jr, Neumann PJ, Radensky P, Walcoff SD. A flexible approach to evidentiary standards for comparative effectiveness research. Health Aff (Millwood) 2010; 29:1812-1817.

18. Patel K. Health reform's tortuous route to the patient-centered outcomes research institute. Health Aff (Millwood) 2010; 29:1777-1782.

19. Congressional Budget Office. Budget options Volume I Health Care. December 2008. www.cbo.gov/ftpdocs/99xx/ doc9925/12-18-HealthOptions.pdf

20. Congressional Budget Office. Research on the Comparative Effectiveness of Medical Treatments. December 2007. www.cbo.gov/ftpdocs/88xx/doc8891/1218-ComparativeEffectiveness.pdf

21. Rethinking Comparative Effectiveness Research. Biotechnology Healthcare 2009; 6:35-36,38. www.ncbi.nlm. nih.gov/pmc/articles/PMC2799075/pdf/ btho6_2po35.pdf

22. Guiding the guidelines. Lancet 2011; 377:1125.

23. Graham R, Mancher M, Wolman DM, Greenfield S, Steinberg E (eds); Committee on Standards for Systematic Reviews of Comparative Effectiveness Research; Institute of Medicine. Clinica Practice Guidelines We Can Trust. The National Academies Press, Washington, DC, 2011.

24. Liberati A, Altman DG, TetzlaffJ, Mulrow C, Gøtzsche PC, loannidis JP, Clarke M, Devereaux PJ, Kleijnen J, Moher D. The PRISMA statement for reporting systematic reviews and meta-analyses of studies that evaluate health care interventions: Explanation and elaboration. Ann Intern Med 2009; 151:W65-W94.

25. Moher D, Cook DJ, Eastwood S, Olkin I, Rennie D, Stroup DF. Improving the quality of reports of meta-analyses of randomised controlled trials: The QUOROM statement. Quality of reporting of met-analyses. Lancet 1999; 354:18961900.

26. Altman DG, Schulz KF, Moher D, Egger M, Davidoff F, Elbourne D, Gøtzsche PC, Lang T; CONSORT GROUP (Consolidated Standards of Reporting Trials). The revised CONSORT statement for reporting randomized trials: Explanation and elaboration. Ann Intern Med 2001; 134:663-694.

27. Vandenbroucke JP, von Elm E, Altman DG, Gøtzsche PC, Mulrow CD, Pocock S), Poole C, Schlesselman JJ, Egger M; STROBE Initiative. Strengthening the Reporting of Observational Studies in Epidemiology (STROBE): Explanation and elaboration. Ann Intern Med 2007; 147: W163-W194.

28. Stroup DF, Berlin JA, Morton SC, Olkin I, Williamson GD, Rennie D, Moher D, Becker BJ, Sipe TA, Thacker SB. Metaanalysis of observational studies in epidemiology: A proposal for reporting. Meta-analysis of Observational Studies in Epidemiology (MOOSE) group. JAMA 2000; 283:2008-2012.

29. Bossuyt PM, Reitsma JB, Bruns DE, Gatsonis CA, Glasziou PP, Irwig LM, Lijmer JG, Moher D, Rennie D, de Vet HC; Standards for Reporting of Diagnostic Accuracy. Towards complete and accurate reporting of studies of diagnostic accuracy: The STARD Initiative. Ann Intern Med 2003; 138:40-44.

30. Manchikanti L, Boswell MV, Singh V, Benyamin RM, Fellows B, Abdi S, Buenaventura RM, Conn A, Datta S, Derby R, Falco FJE, Erhart S, Diwan S, Hayek SM, Helm S, Parr AT, Schultz DM, Smith HS, Wolfer LR, Hirsch JA. Comprehensive evidence-based guidelines for interventional techniques in the management of chronic spinal pain. Pain Physician 2009; 12:699-802.

31. Manchikanti L. Evidence-based medicine, systematic reviews, and guidelines in interventional pain management: Part 1: Introduction and general considerations. Pain Physician 2008; 11:161-186.

32. Manchikanti L, Hirsch JA, Smith HS. Evidence-based medicine, systematic reviews, and guidelines in interventional pain management: Part 2: Randomized controlled trials. Pain Physician 2008; 11:717-773.

33. Manchikanti L, Benyamin RM, Helm S, Hirsch JA. Evidence-based medicine, systematic reviews, and guidelines in interventional pain management: Part 3: Systematic reviews and meta-analysis of randomized trials. Pain Physician 2009; 
12:35-72.

34. Manchikanti L, Singh V, Smith HS, Hirsch JA. Evidence-based medicine, systematic reviews, and guidelines in interventional pain management: Part 4: Observational studies. Pain Physician 2009; 12:73-108.

35. Manchikanti L, Derby R, Wolfer LR, Singh V, Datta S, Hirsch JA. Evidencebased medicine, systematic reviews, and guidelines in interventional pain management: Part 5. Diagnostic accuracy studies. Pain Physician 2009; 12:517-540.

36. Manchikanti L, Datta S, Smith HS, Hirsch JA. Evidence-based medicine, systematic reviews, and guidelines in interventional pain management: Part 6. Systematic reviews and meta-analyses of observational studies. Pain Physician 2009; 12:819-850.

37. Manchikanti L, Derby $R$, Wolfer LR, Singh V, Datta S, Hirsch JA. Evidencebased medicine, systematic reviews, and guidelines in interventional pain management: Part 7: Systematic reviews and meta-analyses of diagnostic accuracy studies. Pain Physician 2009; 12:929-963.

38. Manchikanti L, Falco FJE, Boswell MV, Hirsch JA. Facts, fallacies, and politics of comparative effectiveness research: Part 1. Basic considerations. Pain Physician 2010; 13:E23-E54.

39. Manchikanti L, Falco FJE, Boswell MV, Hirsch JA. Facts, fallacies, and politics of comparative effectiveness research: Part 2. Implications for interventional pain management. Pain Physician 2010; 13:E55-E79.

40. Manchikanti L, Datta S, Derby R, Wolfer LR, Benyamin RM, Hirsch JA. A critical review of the American Pain Society clinical practice guidelines for interventional techniques: Part 1. Diagnostic interventions. Pain Physician 2010; 13:E141E174.

41. Manchikanti L, Datta S, Gupta S, Munglani R, Bryce DA, Ward SP, Benyamin RM, Sharma ML, Helm II S, Fellows B, Hirsch JA. A critical review of the American Pain Society clinical practice guidelines for interventional techniques: Part 2. Therapeutic interventions. Pain Physician 2010; 13:E215-E264.

42. Bigos SJ, Boyer OR, Braen GR, Brown K, Deyo R. Acute Low Back Problems in Adults. Clinical Practice Guideline Number 4. AHCPR Publication No. 95-0642. Agency for Health Care Policy and Research, Public Health Service, US Department of Health and Human Servic- es, Rockville, December 1994

43. Gray BH, Gusmano MK, Collins SR. AH CPR and the changing politics of health services research. Health Aff (Milwood) 2003; W3:283-307.

44. Gonzalez EG. Preface. In: Gonzalez ER, Materson RS (eds). The Nonsurgical Management of Acute Low Back Pain. Demos Vermande, New York, 1997, pp vii-viii.

45. Gonzalez EG, Materson RS. The guidelines, the controversy, the book. In: Gonzalez ER, Materson RS (eds). The Nonsurgical Management of Acute Low Back Pain. Demos Vermande, New York, 1997, pp 1-4

46. Harrington SE. Incentivizing Comparative Effectiveness Research. Ewing Marion Kauffman Foundation Research Paper. January 1, 2011. http://hcmg.wharton. upenn.edu/documents/research/Harrington\%2oincentivizing\%20CER\%20 1\%2011.pdf

47. Keyhani S, Kim A, Mann M, Korenstein $D$. A new independent authority is needed to issue national health care guidelines. Health Aff (Milwood) 2011; 30:256265.

48. Classen DC, Resar R, Griffin F, Federico F, Frankel T, Kimmel N, Whittington JC, Frankel A, Seger A, James BC. "Global trigger tool" shows that adverse events in hospitals may be ten times greater than previously measured. Health Aff (Millwood) 2011; 30:581-589.

49. Kohn LT, Corrigan JM, Donaldson MS (eds). To Err Is Human: Building a Safer Health System. National Academies Press, Washington, DC, 2000.

50. Altman DE, Clancy C, Blendon RJ. Improving patient safety - five years after the IOM report. $N$ Engl ] Med 2004; 351:2041-2043

51. Barach P, Berwick DM. Patient safety and the reliability of health care systems. Ann Intern Med 2003; 138:997-998.

52. Leape LL, Berwick DM, Bates DW. What practices will most improve safety? Evidence-based medicine meets patient safety. JAMA 2002; 288:501-507.

53. McGlynn EA, Asch SM, Adams J, Keesey J, Hicks J, DeCristofaro A, Kerr EA. The quality of health care delivered to adults in the United States. N Engl ] Med 2003; 348:2635-2645.

54. Leape LL, Berwick DM. Five years after to err is human: What have we learned? JAMA 2005; 293:2384-2390.

55. Landrigan $C P$, Parry G), Bones $C B$ Hackbarth AD, Goldmann DA, Sharek PJ. Temporal trends in rates of patient harm resulting from medical care. $N$ Engl ] Med 2010; 363:2124-2134.

56. Brennan TA, Gawande A, Thomas E, Studdert D. Accidental deaths, saved lives, and improved quality. $N$ Engl ] Med 2005; 353:1405-1409.

57. McCannon CJ, Schall MW, Calkins DR, Nazem AG. Saving 100,000 lives in US hospitals. BM] 2006; 332:1328-1330.

58. West AN,Weeks WB, Bagian JP. Rare adverse medical events in VA inpatient care: Reliability limits to using patient safety indicators as performance measures. Health Serv Res 2008; 43:249-266.

59. Brennan TA, Leape LL, Laird N, Herbert L, Localio AR, Lawthers AG, Newhouse JP, Weiler PC, Hiatt HH. Incidence of adverse events and negligence in hospitalized patients. Results of the Harvard Medical Practice Study I. N Engl J Med 1991; 324:370-376.

6o. Institute for Healthcare Improvement. Introduction to Trigger Tools for Identifying Adverse Events. www.ihi.org/IHI/Topics/ PatientSafety/SafetyGeneral/Tools/IntrotoTriggerToolsforldentifyingAEs.html

61. Perencevich EN, Lautenbach E. Infection prevention and comparative effectiveness research. JAMA 2011; 305:14821483.

62. Schaefer MK, Jhung $M$, Dahl M, Schillie S, Simpson C, Llata E, Link-Gelles R, Sinkowitz-Cochran R, Patel P, Bolyard E, Sehulster L, Srinivasan A, Perz JF. Infection control assessment of ambulatory surgical centers. JAMA 2010; 303:22732279.

63. Barie PS. Comment on: Infection control practices in ambulatory surgery centers. JAMA 2010; 303:2273-2279.

64. Manchikanti L, Parr AT, Singh V, Fellows B. Ambulatory surgery centers and interventional techniques: A look at long-term survival. Pain Physician 2011; 14:E177-E215.

65. US Department of Health and Human Services. Centers for Medicare and Medicaid Services (CMS). State Operations Manual Appendix A - Survey Protocol, Regulations and Interpretive Guidelines for Hospitals. Rev. 47, June 5 , 2009.

66. Siegel JD, Rhinehart E, Jackson M, Chiarello $\mathrm{L}$, and the Healthcare Infection Control Practices Advisory Committee, 2007 Guideline for Isolation Precautions: Preventing Transmission of Infectious Agents in Healthcare Settings www.cdc.gov/ncidod/dhqp/pdf/isolation2007.pdf 
67. Centers for Disease Control (CDC) and Prevention. Clinical Reminder: Spinal injection procedures performed without a facemask pose risk for bacterial meningitis.

www.cdc.gov/injectionsafety/PDF/Clinical_Reminder_Spinal-Infection_Meningitis.pdf

68. Agency for Healthcare Research and Quality (AHRQ). Screening for Breast Cancer Recommendation Statement. November 2009; Updated December 2009.

www.ahrq.gov/clinic/USpstf/uspsbrca. htm\#summary.

69. Kopans DB. The recent US preventive services task force guidelines are not supported by the scientific evidence and should be rescinded. J Am Coll Radiol 2010; 7:260-264.

70. Tsai SA, Stefanick ML, Stafford RS. Trends in menopausal hormone therapy use of US office-based physicians, 20002009. Menopause 2010. [Epub ahead of print]

71. Rees M. Emerging facade of menopausal hormone therapy. Semin Reprod Med 2010; 28:351-359.

72. Manchikanti L, Singh V, Derby R, Schultz DM, Benyamin RM, Prager JP, Hirsch JA. Reassessment of evidence synthesis of occupational medicine practice guidelines for interventional pain management. Pain Physician 2008; 11:393482.

73. Health Technology Assessment, Washington State Health Care Authority. Spinal Injections, Final Report. Spectrum Research, Inc., December 14, 2010. www.hta.hca.wa.gov/documents/spinal_injection_final_report.pdf

74. Dupler M. State may stop funding for spinal injections. Tri City Herald, March 18, 2011.

75. Letter to Robin Hashimoto, Washington State Health Care Authority, from American Society of Interventional Pain Physicians RE Health Technology Assessment for Spinal Injections, November 24, 2010.

76. Health Technology Assessment, Washington State Health Care Authority. Spinal Injections, Updated Final Evidence Report. Spectrum Research, Inc., March 10, 2011.

www.hta.hca.wa.gov/documents/updated_final_report_spinal_injections_0310-1.pdf

77. Manchikanti L, Giordano J, Fellows B,
Hirsch JA. Placebo and nocebo in interventional pain management: A friend of a foe - or simply foes? Pain Physician 2011; 14:E157-E175.

78. Evans H. Comparative effectiveness in health care reform: Lessons from abroad. Backgrounder No. 2239; February 4, 2009.

79. Elshaug AG, Garber AM. How CER could pay for itself - insights from vertebral fracture treatments. $N$ Engl J Med 2011; 364:1390-1393.

8o. Kallmes DF, Comstock BA, Heagerty PJ Turner JA, Wilson DJ, Diamond TH, Edwards R, Gray LA, Stout L, Owen S, Hollingworth W, Ghdoke B, Annesley-Williams DJ, Ralston SH, Jarvik JG. A randomized trial of vertebroplasty for osteoporotic spinal fractures. $N$ Engl J Med 2009; 361:569-579.

81. Buchbinder R, Osborne RH, Ebeling PR, Wark JD, Mitchell P, Wriedt C, Graves S, Staples MP, Murphy B. A randomized trial of vertebroplasty for painful osteoporotic vertebral fractures. $N$ Engl J Med 2009; 361:557-568.

82. Brown SR. Scurvy: How a Surgeon, a Mariner, and a Gentleman Solved the Greatest Medical Mystery of the Age of Sail. St. Martin's Press, New York, 2003.

83. Codman EA. A Study in Hospital Efficiency. Privately printed, Boston, Mass, 1916.

84. Committee on Comparative Effectiveness Research Prioritization, Institute of Medicine. Initial National Priorities for Comparative Effectiveness Research. National Academy of Sciences, Washington, DC, 2009.

85. Sackett DL, Rosenberg WM, Gray JA, Haynes RB, Richardson WS. Evidence based medicine: What it is and what it isn't. BMJ 1996; 312:71-72.

86. Selker HP. Comparative effectiveness research: Medical practice, payments, and politics: The need to retain standards of medical research. ] Gen Intern Med 2009; 24:776-778.

87. Eden J, Wheatley B, McNeil B, Sox H. Knowing What Works in Health Care: $A$ Roadmap for the Nation. National Academies Press, Washington, DC, 2008.

88. Garber AM, Tunis SR. Does comparative effectiveness research threaten personalized medicine? New Engl ] Med 2009; 360:1925-1927.

89. Lauer MS. Comparative effectiveness research: The view from the NHLBI.] Am Coll Cardiol 2009; 53:1084-1086.
90. Cook DA. Trojan horse reportedly seen rolling down Pennsylvania Avenue. J Med Assoc Ga 2009; 98:4.

91. H.R. 1. The Medicare Prescription Drug, Improvement, and Modernization Act of 2003, P.L. 108-173, Enacted December 8, 2003.

92. Public Law No: 111-5. H.R. 1. American Recovery and Reinvestment Act of 2009 signed by President Barack Obama on 2/17/2009.

93. Steinbrook R. Health care and the American recovery and reinvestment act. $N$ Engl J Med 2009; 360:1057-1060.

94. Sanders D, Coulter A, McPherson K. Variations in Hospital Admission Rates: A Review of the Literature. King Edward's Hospital Fund for London, London, 1989, p 31.

95. Cochrane A. Effectiveness and Efficiency: Random Reflections on Health Services Nuffield Provincial Hospitals Trust, Leeds, 1972.

96. Stevens A, Milne R, Burls A. Health Technology Assessment: History and Demand. J Public Health Med 1998; 25:98-101.

97. Perry S. The brief life of the National Center for Healthcare Technology. New Engl ] Med 1982; 307:1095-1100.

98. Office of Technology Assessment. Identifying Health Technologies that Work: Searching for Evidence, OTA-H-608. September 1994.

99. U.S. Department of Health and Human Services, Agency for Healthcare Research and Quality. www.ahrq.gov

100. Jarrett A.T. Effect of the Medicare Prescription Drug Improvement and Modernization Act on the bottom line. Am J Health Syst Pharm 2006; 63:S10-S13.

101. Wilensky GR. Implementing the MMA. Healthc Financ Manage 2004; 58:30-32.

102. Agency for Healthcare Research and Quality. Effective Health Care Program. www.effectivehealthcare.ahrq.gov

103. The Congress of the United States Congressional Budget Office. A CBO Paper - Research on the Comparative Effectiveness of Medical Treatments: Issues and Options for an Expanded Federal Role. December 2007.

104. AcademyHealth Report. Placement, Coordination, and Funding of Health Services Research within the Federal Government. AcademyHealth, September 2005.

105. Emanuel EJ. Healthcare Guaranteed. Public Affairs, New York, 2008. 
106. Conway PH, Clancy C. Comparative-effectiveness research - implications of the Federal Coordinating Council's Report. N Engl J Med 2009; 361:328-330.

107. Federal Coordinating Council for Comparative Effectiveness Research. Report to the President and Congress. Washington, DC: Department of Health and Human Services, June 2009. www.hhs. gov/recovery/programs/cer/cerannualrpt.pdf

108. Partnership to Improve Patient Care. A Procedural Framework for the Conduct of Comparative Clinical Effectiveness Research. November 2010. www.improvepatientcare.org/sites/default/files/CER Procedure-PIPC_Whitepaper.pdf

109. Department of Health and Human Services. Federal Register, Volume 75, No. 4. Medicare Prescription Drug, Improvement, and Modernization Act of $2003 \mathrm{Sec}-$ tion 1013: Request for Nominations - the Effective Healthcare Stakeholder Group. Notice of invitation to submit nominations for the Effective Health Care Stakeholder Group. January 7, 2010. www.gpo.gov/fdsys/pkg/FR-2010-01-07/ pdf/E9-31341.pdf

110. Agency for Health Care Research and Quality. Fact Sheet. Reinvestment Act Investments in Comparative Effectiveness Research for a Community Forum. www. ahrq.gov/fund/cerfactsheets/cerfsforum.pdf

111. Partnership to Improve Patient Care. Priority-Setting for Comparative Effectiveness Research: A Review of Key Elements. March 2011. www.improvepatientcare.org/sites/default/files/Priority-Setting\%2ofor\%20Comparative\%2oEffectiveness\%2oResearch\%20-\%20A\%20 Review\%20of\%2oKey\%2oElements.pdf

112. Donaldson MS, Sox HC (eds). Setting Priorities for Health Technology Assessment: A Model Process. National Academy Press;, Washington, DC, 1992.

113. Sibbald SL, Singer PA, Upshur R, Martin DK. Priority setting: What constitutes success? A conceptual framework for successful priority setting. BMC Health Serv Res 2009; 9:43.

114. Comments to IOM Committee on Comparative Effectiveness Research Priorities. Speaker testimonies, March 20, 2009. www.iom.edu/ /media/Files/Activity\%2oFiles/Research/CERPriorities/ SpeakerTestimonies910AMblockv3.ashx

115. McNutt RA, Livingston EH. Evidencebased medicine requires appropriate clinical context. JAMA 2010; 303:454-455.
116. Relman AS. Doctors as the key to health care reform. $N$ Engl J Med 2009; 361:1225-1227.

117. Kopans DB. The 2009 US Preventive Services Task Force (USPSTF) guidelines are not supported by science: The scientific support for mammography screening. Radiol Clin North Am 2010; 48:843857.

118. Gregory KD, Sawaya GF. Updated recommendations for breast cancer screening. Curr Opin Obstet Gynecol 2010; 22:498-505.

119. Squiers LB, Holden DJ, Dolina SE, Kim $A E$, Bann CM, Renaud JM. The public's response to the U.S. Preventive Services Task Force's 2009 recommendations on mammography screening. Am J Prev Med 2011; 40:497-504.

120. Hendrick RE, Helvie MA. United States Preventive Services Task Force screening mammography recommendations: Science ignored. AJR Am J Roentgenol 2011; 196:W112-W116.

121. Kettritz U. Screening of breast cancer an eternal discussion revisited? Breast Care (Basel) 2010; 5:119-120.

122. Campos-Outcalt D. USPSTF recommendations you may have missed amid the breast cancer controversy. J Fam Pract 2010; 59:276-280.

123. Javitt MC, Hendrick RE. Revealing $\mathrm{Oz}$ behind the curtain: USPSTF screening mammography guidelines and the hot air balloon. AJR Am J Roentgenol 2010; 194:289-290.

124. Caplan LS. To screen or not to screen: The issue of breast cancer screening in older women. Public Health Rev 2001; 29:231-240.

125. Rathore SS, McGreevey JD 3rd, Schulman KA, Atkins D. Mandated coverage for cancer-screening services: Whose guidelines do states follow? Am J Prev Med 2000; 19:71-78.

126. Steinbrook R. Guidance for guidelines. N Engl J Med 2007; 356:331-333.

127. Chou R. Same trials, different conclusions: Sorting out discrepancies between reviews on interventional procedures of the spine. Spine J 2009; 9:679689.

128. Shaneyfelt TM, Mayo-Smith MF, Rothwangl J. Are guidelines following guidelines? The methodological quality of clinical practice guidelines in the peer reviewed medical literature. JAMA 1999; 281:1900-1905.

129. Levin JH. Prospective, double-blind, randomized placebo-controlled trials in interventional spine: What the highest quality literature tells us. Spine ] 2009; 9:690-703.

130. Manchikanti L, Shah RV, Datta S, Singh V. Critical evaluation of interventional pain management literature provides inaccurate conclusions. Spine J 2009; 9:706-708.

131. Chou R, Atlas SJ, Stanos SP, Rosenquist RW. Nonsurgical interventional therapies for low back pain: A review of the evidence for an American Pain Society clinical practice guideline. Spine (Phila $\mathrm{Pa}$ 1976) 2009; 34:1078-1093.

132. Chou R, Huffman L. Guideline for the Evaluation and Management of Low Back Pain: Evidence Review. American Pain Society, Glenview, IL, 2009.

www.ampainsoc.org/pub/pdf/LBPEvidRev.pdf

133. Chou R, Loeser JD, Owens DK, Rosenquist RW, Atlas S), Baisden J, Carragee EJ, Grabois M, Murphy DR, Resnick DK, Stanos SP, Shaffer WO, Wall EM; American Pain Society Low Back Pain Guideline Panel. Interventional therapies, surgery, and interdisciplinary rehabilitation for low back pain: An evidencebased clinical practice guideline from the American Pain Society. Spine (Phila $\mathrm{Pa}$ 1976) 2009; 34:1066-1077.

134. Datta S, Manchikanti L. In response to Chou R, Loeser JD, Owens DK, et al. Interventional therapies, surgery, and interdisciplinary rehabilitation for low back pain: An evidence-based clinical practice guideline from the American Pain Society. Spine (Phila Pa 1976) 2009; 34:1066-1077; Spine (Phila Pa 1976) 2010 35:1826; author reply 1826-1827.

135. Chou R. Critiquing the critiques: The American Pain Society guideline and the American Society of Interventional Pain Physicians' response to it. Pain Physician 2011; 14:E69-E73; Response: Manchikanti L, Gupta S, Benyamin R, Munglani R, Datta S, Hirsch JA, Ward SP. In response from Manchikanti et al. Pain Physician 2011; 14:E73-E80.

136. Chou R. Letter to the editor: Re: Chou $R$, Loeser JD, Owens DK, et al. Interventional therapies, surgery and interdisciplinary rehabilitation for low back pain: an evidence-based clinical practice guideline from the American Pain Society. Spine (Phila Pa 1976) 2009; 34:10661077. Spine (Phila Pa 1976) 2011; 36:590.

137. American College of Occupational and Environmental Medicine (ACOEM) Low 
back Disorders. In: Occupational Medicine Practice Guidelines: Evaluation and Management of Common Health Problems and Functional Recovery of Workers, Second Edition. American College of Occupational and Environmental Medicine Press, Elk Grove Village, 2007.

138. American College of Occupational and Environmental Medicine (ACOEM) Chronic Pain. In: Occupational Medicine Practice Guidelines: Evaluation and Management of Common Health Problems and Functional Recovery of Workers, Second Edition. American College of Occupational and Environmental Medicine Press, Elk Grove Village, 2008.

139. Weinstein JN. Balancing science and informed choice in decisions about vertebroplasty. N Engl J Med 2009; 361:619621.

140. Hsieh P. HSIEH: Best health care political pull can buy. The Washington Times, January 5, 2011.

141. Hochman M, McCormick D. Characteristics of published comparative effectiveness studies of medications. JAMA 2010; 303:951-958.

142. Avery G. Scientific misconduct. The manipulation of evidence for political advocacy in health care and climate policy. Cato Institute Briefing Papers, No. 117, February 8, 2010.

143. Kloth D. Health care reform - involving our physician leaders. Pain Physician 2011; 14:169-173.

144. Letter to Laxmaiah Manchikanti MD, from Leah Hole-Curry, MD, Washington State Health Care Authority. Re: Washington State Health Technology Assessment. December 9, 2010.

145. Gamble M. Washington State may cut spinal injections from state coverage. Becker's Orthopedic, Spine \& Pain Management, March 18, 2011.

146. Pollack A. A panel decides Washington State's health care costs. The New York Times, March 21, 2011.

147. Fields R. Washington State program to continue payment for some spinal injections. Becker's ASC Review, May 3, 2011.

148. Campbell EG, Zinner DE. Disclosing industry relationships - toward an improved federal research policy. $N$ Engl J Med 2010; 363:604-606.

149. Neumann PJ, Weinstein MC. Legislating against use of cost-effectiveness information. N Engl J Med 2010; 363:14951497.

150. Wolfer L, Derby R, Lee JE, Lee SH. Systematic review of lumbar provocation discography in asymptomatic subjects with a meta-analysis of false-positive rates. Pain Physician 2008; 11:513-538.

151. Atluri S, Datta S, Falco FJE, Lee M. Systematic review of diagnostic utility and therapeutic effectiveness of thoracic facet joint interventions. Pain Physician 2008; 11:611-629.

152. Nelemans $P$, de Bie $R$, de Vet $H$, Sturmans F. WITHDRAWN: Injection therapy for subacute and chronic benign lowback pain. Cochrane Database Syst Rev. 2007; 3:CDoo1824.

153. Niemistö L, Kalso E, Malmivaara A, Seitsalo $\mathrm{S}$, Hurri $\mathrm{H}$. Radiofrequency denervation for neck and back pain: A systematic review within the framework of the Cochrane Collaboration Back Review Group. Spine (Phila Pa 1976) 2003; 28:1877-1888.

154. Manchikanti L, Singh V, Helm S, Schultz DM, Datta S, Hirsch J. An introduction to an evidence-based approach to interventional techniques in the management of chronic spinal pain. Pain Physician 2009; 12:E1-E33.

155. Dennison PL, Kennedy CW. Official Disability Guidelines. 15th ed. Work Loss Data Institute, Encinitas, 2010.

156. Manchikanti L, Singh V, Datta S, Cohen SP, Hirsch JA. Comprehensive review of epidemiology, scope, and impact of spinal pain. Pain Physician 2009; 12:E35E7o.

157. Manchikanti L, Boswell MV, Singh V Derby R, Fellows B, Falco FJE, Datta $S$, Smith HS, Hirsch JA. Comprehensive review of neurophysiologic basis and diagnostic interventions in managing chronic spinal pain. Pain Physician 2009; 12:E71-E120.

158. Manchikanti L, Boswell MV, Datta S, Fellows B, Abdi S, Singh V, Benyamin RM, Falco FJE, Helm S, Hayek S, Smith HS. Comprehensive review of therapeutic interventions in managing chronic spinal pain. Pain Physician 2009: 12:E123E198.

159. Manchikanti L, Singh V, Pampati V, Boswell MV, Benyamin RM, Hirsch JA. Description of documentation in the management of chronic spinal pain. Pain Physician 2009: 12:E199-E224.

160. Manchikanti L, Helm S, Singh V, Benyamin RM, Datta S, Hayek S, Fellows B, Boswell MV. An algorithmic approach for clinical management of chronic spinal pain. Pain Physician 2009; 12:E225E264.

161. Falco FJE, Erhart S, Wargo BW, Bryce
DA, Atluri S, Datta S, Hayek SM. Systematic review of diagnostic utility and therapeutic effectiveness of cervical facet joint interventions. Pain Physician 2009; 12:323-344.

162. Datta S, Lee M, Falco FJE, Bryce DA, Hayek SM. Systematic assessment of diagnostic accuracy and therapeutic utility of lumbar facet joint interventions. Pain Physician 2009; 12:437-460.

163. Manchikanti L, Dunbar EE, Wargo BW, Shah RV, Derby R, Cohen SP. Systematic review of cervical discography as a diagnostic test for chronic spinal pain. Pain Physician 2009; 12:305-321.

164. Manchikanti L, Glaser S, Wolfer L, Derby R, Cohen SP. Systematic review of lumbar discography as a diagnostic test for chronic low back pain. Pain Physician 2009; 12:541-559.

165. Conn A, Buenaventura R, Datta S, Abdi S, Diwan S. Systematic review of caudal epidural injections in the management of chronic low back pain. Pain Physician 2009; 12:109-135.

166. Parr AT, Diwan S, Abdi S. Lumbar interlaminar epidural injections in managing chronic low back and lower extremity pain: A systematic review. Pain Physician 2009; 12:163-188.

167. Benyamin RM, Singh V, Parr AT, Conn A, Diwan S, Abdi S. Systematic review of the effectiveness of cervical epidurals in the management of chronic neck pain. Pain Physician 2009; 12:137-157.

168. Buenaventura RM, Datta S, Abdi S, Smith HS. Systematic review of therapeutic lumbar transforaminal epidural steroid injections. Pain Physician 2009; 12:233-251.

169. Helm S, Hayek S, Benyamin RM, Manchikanti L. Systematic review of the effectiveness of thermal annular procedures in treating discogenic low back pain. Pain Physician 2009; 12:207-232.

170. Smith HS, Chopra P, Patel VB, Frey ME, Rastogi R. Systematic review on the role of sedation in diagnostic spinal interventional techniques. Pain Physician 2009; 12:195-206.

171. Frey ME, Manchikanti L, Benyamin RM, Schultz DM, Smith HS, Cohen SP. Spinal cord stimulation for patients with failed back surgery syndrome: A systematic review. Pain Physician 2009; 12:379397.

172. Epter RS, Helm S, Hayek SM, Benyamin RM, Smith HS, Abdi S. Systematic review of percutaneous adhesiolysis and management of chronic low back pain 
in post lumbar surgery syndrome. Pain Physician 2009; 12:361-378.

173. Patel VB, Manchikanti L, Singh V, Schultz DM, Hayek SM, Smith HS. Systematic review of intrathecal infusion systems for long-term management of chronic non-cancer pain. Pain Physician 2009; 12:345-36o.

174. Rupert MP, Lee M, Manchikanti L, Datta $S$, Cohen SP. Evaluation of sacroiliac joint interventions: A systematic appraisal of the literature. Pain Physician 2009; 12:399-418.

175. Hayek SM, Helm S, Benyamin RM, Singh V, Bryce DA, Smith HS. Effectiveness of spinal endoscopic adhesiolysis in post lumbar surgery syndrome: A systematic review. Pain Physician 2009; 12:419-435.

176. Hirsch JA, Singh V, Falco FJE, Benyamin RM, Manchikanti L. Automated percutaneous lumbar discectomy for the contained herniated lumbar disc: A systematic assessment of evidence. Pain Physician 2009; 12:601-620.

177. Singh V, Manchikanti L, Benyamin RM, Helm S, Hirsch JA. Percutaneous lumbar laser disc decompression: A systematic review of current evidence. Pain Physician 2009; 12:573-588.

178. Singh V, Benyamin RM, Datta S, Falco FJE, Helm S, Manchikanti L. Systematic review of percutaneous lumbar mechanical disc decompression utilizing Dekompressor®. Pain Physician 2009; 12:589-599.

179. Manchikanti L, Derby R, Benyamin RM, Helm S, Hirsch JA. A systematic review of mechanical lumbar disc decompression with nucleoplasty. Pain Physician 2009; 12:561-572.

180. Helm S. California workers' compensation system: Are occupational medicine practice guidelines sufficient for the treatment of chronic spinal pain or do they require supplementation by guidelines for interventional techniques? Pain Physician 2004; 229-238.

181. Cushner FD, Nett MP. Unanswered questions, unmet needs in venous thromboprophylaxis. Orthpedics 2009; 32:62-66.

182. Lo B, Field MJ, eds. Conflict of Interest in Medical Research, Education, and Practice. Institute of Medicine, National Academy Press, Washington, D.C., 2009.

183. Canan P, Kretzmann M, Hennessy M, Pring GW. Using law ideologically: The conflict between economic and political liberty. J Law Polit 1992; 8:539-58.
184. Gatchel RJ, McGeary D. Cochrane collaboration-based reviews of health care interventions: Are they unequivocal and valid scientifically, or simply nihilistic? Spine J 2002; 2:315-319.

185. Mowatt G, Shirran L, Grimshaw JM, Rennie D, Flanagin A, Yank V, MacLennan G, Gotzsche PC, Bero LA. Prevalence of honorary and ghost authorship in Cochrane Reviews. JAMA 2002; 287:2769-2771.

186. Errico TJ, Gatchel RJ, Schofferman J, Benzel EC, Faciszewski T, Eskay-Auerbach M, Wang JC. A fair and balanced view of spine fusion surgery. Spine ] 2004; 4:S129-S138.

187. LaDou J, Teitelbaum DT, Egilman DS, Frank AL, Kramer SN, Huff J. American College of Occupational and Environmental Medicine (ACOEM): A professional association in service to industry. Int J Occup Environ Health 2007; 13:404426.

188. Greenberg M. Commentary on effects of exposure to industry influence on ACOEM. Int J Occup Environ Health 2007; 13:427.

189. Deyo RA, Psaty BM, Simon G, Wagner $\mathrm{EH}$, Omenn GS. The messenger under attack - intimidation of researchers by special-interest groups. N Engl J Med 1997; 336:1176-1180.

190. Feinstein AR. Clinical Judgment. Robert E. Krieger, Huntington, NY, 1967, pp.220-222.

191. Angell M. Evaluating the health risks of breast implants: The interplay of medical science, the law, and public opinion. N Engl J Med 1996; 334:1513-1518.

192. DuVal G, Clarridge B, Gensler G, Danis $M$. A national survey of U.S. internists' experiences with ethical dilemmas and ethics consultation. J Gen Intern Med 2004; 19:251-258.

193. Vesely AE, De Almeida J. Evidence-based medicine: Part 1: More than just the randomized controlled trial. Univ Toronto Med ] 2002; 2:129-132.

194. Cohen MA. MAST: What went wrong? An essay on the changes in medical practice. Pharos Alph Omega Alpha Honor Med Soc 2000; 63:22-26.

195. Holmberg L, Baum M, Adami HO. On the scientific inference from clinical trials. J Eval Clin Pract 1999; 5:157-162.

196. Smith BH. Evidence based medicine. Quality cannot always be quantified. BM] 1995; 311:258.

197. Carter BJ. Evidence-based decisionmaking: Practical issues in the apprais- al of evidence to inform policy and practice. Aust Health Rev 2010; 34:435-440.

198. Rochon PA, Sekeres M, Hoey J, Lexchin J, Ferris LE, Moher D, Wu W, Kalkar SR, Van Laethem M, Gruneir A, Gold J, Maskalyk J, Streiner DL, Taback N, Chan AW. Investigator experiences with financial conflicts of interest in clinical trials. Trials 2011; 12:9.

199. Roseman M, Milette K, Bero LA, Coyne JC, Lexchin J, Turner EH, Thombs BD. Reporting of conflicts of interest in meta-analyses of trials of pharmacological treatments. JAMA 2011; 305:1008-1017.

200. Fauber J. UW a force in pain drug growth. Journal Sentinel, April 2, 2011.

201. O'Reilly KB. Financial ties to industry widespread on clinical guideline panels. American Medical News, April 11, 2011.

202. Mendelson TB, Meltzer M, Campbell EG, Caplan AL, Kirkpatrick JN. Conflicts of interest in cardiovascular clinical practice guidelines. Arch Intern Med 2011; 171:577-584.

203. Lo B, Kelch RP, Grady D. Invited commentary-llluminating physicians' financial relationships with industry. Arch Intern Med 2011; 171:587-589.

204. Code for Interactions with Companies. Council of Medical Specialty Societies. March 2011.

www.cmss.org/uploadedfiles/site/ cmss_policies/cmss\%2ocode\%2o for\%2ointeractions\%2owith\%20companies $\% 20$ approved $\% 2$ orevised $\% 20$ version\%203-19-11clean.pdf

205. American Society of Interventional Pain Physicians (ASIPP). Conflict of Interest Policy.

www.asipp.org/documents/ASIPPCOIFinalo32010_000.pdf

206. O'Reilly KB. Million-dollar payouts to researchers often go undisclosed in journal articles. American Medical News, September 27, 2010.

207. Detsky AS. Sources of bias for authors of clinical practice guidelines. CMAJ 2006; 175:1033,1035.

208. Murphy MK, Black NA, Lamping DL, McKee CM, Sanderson CF, Askham J, Marteau T. Consensus development methods, and their use in clinical guideline development. Health Technol Assess 1998; 2:i-iv,1-88.

209. Ayanian J Z, Landrum MB, Normand SL, Guadagnoli E, McNeil BJ. Rating the appropriateness of coronary angiography_do practicing physicians agree with an expert panel and with each other? N Engl] Med 1998; 338:1896-1904. 
210. Kahan JP, Park RE, Leape LL, Bernstein S), Hilborne LH, Parker L, Kamberg C), Ballard DJ, Brook RH. Variations by specialty in physician ratings of the appropriateness and necessity of indications for procedures. Med Care 1996; 34:512523.

211. Fitch K, Lázaro P, Aguilar MD, Martin Y, Bernstein S). Physician recommendations for coronary revascularization: Variations by clinical specialty. Euro J Public Health 1999; 9:181-187.

212. Lo B, Field MJ (eds). Conflicts of interest and development of clinical practice guidelines. In: Conflict of Interest in Medical Research, Education, and Practice. Institute of Medicine, National Academy Press, Washington, DC, 2009, pp 189215 .

213. Chou R, Huffman L. Use of Chronic Opioid Therapy in Chronic Noncancer Pain: Evidence Review. American Pain Society, Glenview, IL, 2009. www.ampainsoc.org/pub/pdf/Opioid_ Final_Evidence_Report.pdf

214. Model Policy for the Use of Controlled Substances for the Treatment of Pain. The Federation of State Medical Boards of the United States. Inc., May 2004.

215. Daniels N, Sabin J. Limits to health care: Fair procedures, democratic deliberation, and the legitimacy problem for insurers. Philos Public Aff 1997; 26:303-350.

216. Daniels N. Accountability for reasonableness. BM] 2000; 321:1300-1301.

217. Coulter A, Ham C (eds). The Global Challenge of Health Care Rationing. Open University Press, Buckingham, 2000.

218. The National Working Group on Evidence-Based Health Care. The Role of the Patient/Consumer in Establishing a Dynamic Clinical Research Continuum: Models of Patient/Consumer Inclusion. August 2008

219. Department of Health and Human Services, Centers for Medicare \& Medicaid Services. 42 CFR Parts 405, 409, 410, 411, 413, 414, 415, and 424 Medicare Program; Payment Policies Under the Physician Fee Schedule and Other Revisions to Part B for CY 2011; Final Rule. November 29, 2010.

220. Department of Health and Human Services, Centers for Medicare \& Medicaid Services. 42 CFR Parts 410, 411, 412, 413, 416, 419, and 489. Medicare Program: Hospital Outpatient Prospective Payment System and CY 2011 Payment Rates; Ambulatory Surgical Center Payment System and CY 2011 Payment
Rates; Payments to Hospitals for Graduate Medical Education Costs; Physician Self-Referral Rules and Related Changes to Provider Agreement Regulations; Payment for Certified Registered Nurse Anesthetist Services Furnished in Rural Hospitals and Critical Access Hospitals. Final Rule. November 24, 2010.

221. Department of Health and Human Services, Centers for Medicare \& Medicaid Services. 42 CFR Parts 412, 413, 415, et al. Medicare Program; Hospital Inpatient Prospective Payment Systems for Acute Care Hospitals and the Long Term Care Hospital Prospective Payment System Changes and FY2011 Rates; Provider Agreements and Supplier Approvals; and Hospital Conditions of Participation for Rehabilitation and Respiratory Care Services; Medicaid Program: Accreditation for Providers of Inpatient Psychiatric Services; Final Rule. August 16, 2010.

222. The Lewin Group for the Commonwealth Fund, 2007.

223. National Institute for Health and Clinical Excellence (NICE). www.nice.org.uk

224. Nasty truth about NICE: It's the body that rations nhs drugs. but this leading cancer specialist says its decisions are deeply flawed, The Daily Mail, August 8 , 2008.

225. Timmins N. Letter from Britain: Across the pond, giant new waves of health reform. Health Aff (Milwood) 2010; 29:21382141.

226. Department of Health (UK). Equity and Excellence: Liberating the NHS. London, July 2010. www.dh.gov.uk/prod_consum_dh/groups/dh_digitalassets/@ dh/@en/@ps/documents/digitalasset/ dh_117794.pdf

227. HM Government. The Coalition: Our Programme for Government. London, May 2010. www.cabinetoffice.gov.uk/ media/409088/pfg_coalition.pdf

228. Department of Health (UK). Speech by the Rt Hon Andrew Lansley CBE MP, Secretary of State for Health, 8 June 2010, "My Ambition for Patient-Centred Care." London, June 2010. www.dh.gov.uk/en/ MediaCentre/Speeches/DH_116643

229. Department of Health (UK). Andrew Lansley: GP Commissioning and the Future of the NHS. London, October 2010. www.dh.gov.uk/en/MediaCentre/ Speeches/DH_120666

230. Nuffield Trust. 2010 John Fry Fellowship Lecture: What GP Commissioning Consortia Might Learn From the Devel- opment of Physician Groups in the US: A Synthesis of 20 Years Experience to Avoid Failure. London, October 2010. www.nuffieldtrust.org.uk/events/detail. aspx?id $=46 \&$ prID=734\&year $=2010$

231. Royal College of General Practitioners. Department of Health Consultation on Equity and Excellence: Liberating the NHS. London, October, 2010. www.rcgp.org. uk/pdf/RCGP_response_to_Equity_ and_Excellence_Liberating_the_NHS. pdf

232. King's Fund. Impact of the Health White Paper: What Do Doctors Think? London, October 2010. www.kingsfund.org.uk/ current_projects/the_nhs_white_paper/ impact_of_the_health.html

233. King's Fund. The King's Fund Response to the NHS White Paper. London, October 2010. www.kingsfund.org.uk/current_ projects/the_nhs_white_paper/the_ kings_fund.html

234. Timmins N. The NICE way of influencing health spending: A conversation with Sir Michael Rawlins. Health Aff (Millwood) 2009; 28:1360-1365.

235. Editor's blog Wednesday 3 November 2010: A NICE surprise. Health Policy Insight. November 2010. www.healthpolicyinsight.com/?q=node/836

236. Beckford M. NHS shamed over callous treatment of elderly. The Telegraph, February 14, 2011.

237. Healy B. Commentary: Health reform, an assault on doctor-patient choice. U.S. News and World Report, November 22, 2009.

238. Houssami N, Abraham LA, Miglioretti DL, Sickles EA, Kerlikowske K, Buist DS, Geller BM, Muss HB, Irwig L. Accuracy and outcomes of screening mammography in women with a personal history of early-stage breast cancer. JAMA 2011; 305:790-799.

239. The separation of health and state. Wall Street Journal, April 6, 2010. http://docsupatientcare.org/_blog/Blog_and_ News/post/The_Separation_of_Health_ and_State,_The_Wall_Street_Journal,_ April_6,_2010/

240. Pearson SD, Bach PB. How Medicare could use comparative effectiveness research in deciding on new coverage and reimbursement. Health Aff (Millwood) 2010; 29:1796-1804.

241. Milgate K, Hackbarth G. Quality in Medicare: From measurement to payment and provider to patient. Health Care Financ Rev 2005-2006; 27:91-101.

242. Miller RG, Druckman JL. The Patient 
Safety and Quality Improvement Act of 2005 - the federal law and its implications for Missouri. Mo Med 2007; 104:1720.

243. Aspden P, Corrigan JM, Wolcott J, Erickson SM. Patient Safety: Achieving a New Standard for Care. National Academies Press, Washington, DC, 2004.

244. Zhan C, Miller MR. Administrative data based patient safety research: A critical review. Qual Saf Health Care 2003; 12:ii58-ii63.

245. Hougland P, Xu W, Pickard S, Masheter C, Williams SD. Performance of International Classification of Diseases, 9th Revision, Clinical Modification codes as an adverse drug event surveillance system. Med Care 2006; 44:629-636.

246. Masheter CJ, Hougland P, Xu W. Detection of inpatient health care associated injuries: Comparing two ICD-9-CM code classifications. In: Hendriksen K, Battles JB, Marks ES, Lewin DI (eds). Advances in Patient Safety: From Research to Implementation: Volume 1. Agency for Healthcare Research and Quality, Rockville, 2005.

247. US Department of Health and Human Services. Centers for Medicare and Medicaid Services (CMS). State Operations Manual Appendix L-Guidance for Surveyors: Ambulatory Surgical Centers. Rev. 56, December 30, 2009.

248. Anthony T, Murray BW, Sum-Ping JT, Lenkovsky F, Vornik VD, Parker BJ, McFarlin JE, Hartless K, Huerta S. Evaluating an evidence-based bundle for preventing surgical site infection: A randomized trial. Arch Surg 2011; 146:263269.

249. Kim LT. Surgical site infection: Still waiting on the revolution. JAMA 2011; 305:1478-1479.

250. Institute for Healthcare Improvement. Programs: Topics, Critical Care, Intensive Care, Changes. www.ihi.org/IHI/Topics/ CriticalCare/IntensiveCare/Changes

251. Huskins WC, Huckabee CM, O'Grady NP, Murray P, Kopetskie H, Zimmer L, Walker ME, Sinkowitz-Cochran RL, Jernigan JA, Samore M, Wallace D, Goldmann DA; STAR*ICU Trial Investigators. Intervention to reduce transmission of resistant bacteria in intensive care. N Engl J Med 2011; 364:1407-1418.

252. Morris MC, Tangney CC. A potential design flaw of randomized trials of vitamin supplements. JAMA 2011; 305:1348-1349.

253. Manson JE, Mayne ST, Clinton SK. Vitamin $D$ and prevention of cancer--ready for prime time? N Engl J Med 2011; 364:1385-1387.

254. Rubinstein SM, van Tulder M. A best-evidence review of diagnostic procedures for neck and low-back pain. Best Pract Res Clin Rheumatol 2008; 22:471-482.

255. Fairman JA, Rowe JW, Hassmiller S, Shalala DE. Broadening the scope of nursing practice. N Engl J Med 2011; 364:193196.

256. Sox HC, Helfand M, Grimshaw J, Dickersin K; PLoS Medicine Editors, Tovey D, Knottnerus JA, Tugwell P. Comparative effectiveness research: Challenges for medical journals. PLoS Med 2010; 7:e1000269.

257. Kupersmith J, Ommaya AK. The past, present, and future of comparative effectiveness research in the US Department of Veterans Affairs. Am J Med 2010; 123:ez-e7.

258. Chalkidou K, Lord J, Fischer A, Littlejohns P. Evidence-based decision making: when should we wait for more information? Health Aff (Milwood) 2008; 27:1642-1653.

259. Epstein R, Teagarden JR. Comparative effectiveness and personalized medicine: evolving together or apart? Health Aff (Millwood) 2010; 29:1783-1787.

26o. Concato J, Lawler EV, Lew RA, Gaziano JM, Aslan M, Huang GD. Observational methods in comparative effectiveness research. Am J Med 2010; 123:e16-e23.

261. Etheredge LM. Creating a high-performance system for comparative effectiveness research. Health Aff (Millwood) 2010; 29:1761-1767.

262. Benner JS, Morrison MR, Karnes EK, Kocot L, McClellan M. An evaluation of recent federal spending on comparative effectiveness research: Priorities, gaps, and next steps. Health Aff (Millwood) 2010; 29:1768-1776.

263. Cleland K, Peipert JF, Westhoff C, Spear $S$, Trussell J. Family planning as a costsaving preventive health service. $N$ Engl J Med 2011; 364:e37.

264. National Institute for Health and Clinical Excellence (NICE). Low back pain: Early management of persistent nonspecific low back pain. NICE Clinical Guideline 88. May 2009.

265. The National Collaborating Center for Primary Care (NCCPC) Royal College of General Practitioners (RCGP). Low back pain: Early management of persistent non-specific low back pain. Full guideline, May 2009.
266. National Institute for Health and Clinical Excellence (NICE). Percutaneous intradiscal electrothermal therapy for low back pain. NICE Interventional Procedure Guidance 319. November 2009.

267. National Institute for Health and Clinical Excellence (NICE). Percutaneous endoscopic laser lumbar discectomy. NICE Interventional Procedure Guidance 300. May 2009.

268. National Institute for Health and Clinical Excellence (NICE). Keyhole treatment of a prolapsed (slipped) lumbar disc by endoscope-guided laser. Understanding NICE Guidance 300. May 2009.

269. National Institute for Health and Clinical Excellence (NICE). Percutaneous disc decompression using coblation for lower back pain. NICE Interventional Procedure Guidance 173. May 2006.

270. National Institute for Health and Clinical Excellence (NICE). Percutaneous vertebroplasty. NICE Interventional Procedure Guidance 12. September 2003.

271. National Institute for Health and Clinical Excellence (NICE). Spinal cord stimulation for chronic pain of neuropathic or ischaemic origin. NICE Technology Appraisal Guidance. October 2008.

272. Singh V, Manchikanti L, Shah RV, Dunbar EE, Glaser SE. Systematic review of thoracic discography as a diagnostic test for chronic spinal pain. Pain Physician 2008; 11:631-642.

273. Koes BW, Scholten RJ, Mens JM, Bouter LM. Efficacy of epidural steroid injections for low back pain and sciatica: A systematic review of randomized clinical trials. Pain 1995; 63:279-288.

274. West S, King V, Carey TS, Lohr KN, McKoy N, Sutton SF, Lux L. Systems to Rate the Strength of Scientific Evidence. Evidence Report/Technology Assessment No. 47. AHRQ Publication No. O2-Eo16. Agency for Healthcare Research and Quality, Rockville, MD, 2002.

www.thecre.com/pdf/ahrq-systemstrength.pdf

275. Sehgal N, Dunbar EE, Shah RV, Colson JD. Systematic review of diagnostic utility of facet (zygapophysial) joint injections in chronic spinal pain: An update. Pain Physician 2007; 10:213-228.

276. Boswell MV, Colson JD, Sehgal N, Dunbar EE, Epter R. A systematic review of therapeutic facet joint interventions in chronic spinal pain. Pain Physician 2007; 10:229-253. 
277. Abdi S, Datta S, Trescot AM, Schultz DM, Adlaka R, Atluri SL, Smith HS, Manchikanti L. Epidural steroids in the management of chronic spinal pain: A systematic review. Pain Physician 2007; 10:185-212.

278. Datta S, Everett CR, Trescot AM, Schultz DM, Adlaka R, Abdi S, Atluri SL, Smith $H S$, Shah RV. An updated systematic review of diagnostic utility of selective nerve root blocks. Pain Physician 2007; 10:113-128.

279. Trescot AM, Chopra P, Abdi S, Datta S, Schultz DM. Systematic review of effectiveness and complications of adhesiolysis in the management of chronic spinal pain: An update. Pain Physician 2007; 10:129-146.

280. Buenaventura RM, Shah RV, Patel V, Benyamin R, Singh V. Systematic review of discography as a diagnostic test for spinal pain: An update. Pain Physician 2007;
10:147-164.

281. Hansen HC, McKenzie-Brown AM Cohen SP, Swicegood JR, Colson JD, Manchikanti L. Sacroiliac joint interventions: A systematic review. Pain Physician 2007; 10:165-184.

282. Manchikanti L, Singh V, Vilims BD, Hansen HC, Schultz DM, Kloth DS. Medial branch neurotomy in management of chronic spinal pain: Systematic review of the evidence. Pain Physician 2002; 5:405-418.

283. Boswell MV, Colson JD, Spillane WF. Therapeutic facet joint interventions in chronic spinal pain: A systematic review of effectiveness and complications. Pain Physician 2005; 8:101-114.

284. Shah RV, Everett CR, McKenzie-Brown AM, Sehgal N. Discography as a diagnostic test for spinal pain: A systematic and narrative review. Pain Physician 2005; 8:187-209.
285. Abdi S, Datta S, Lucas LF. Role of epidural steroids in the management of chronic spinal pain: A systematic review of effectiveness and complications. Pain Physician 2005; 8:127-143.

286. Andersson GB, Mekhail NA, Block JE. Treatment of intractable discogenic low back pain. A systematic review of spinal fusion and intradiscal electrothermal therapy (IDET). Pain Physician 2006; 9:237-248.

287. Chopra P, Smith HS, Deer TR, Bowman RD. Role of adhesiolysis in the management of chronic spinal pain: A systematic review of effectiveness and complications. Pain Physician 2005; 8:87-100.

288. Taylor RS, Taylor RJ, Van Buyten JP, Buchser E, North R, Bayliss S. The cost effectiveness of spinal cord stimulation in the treatment of pain: A systematic review of the literature. J Pain Symp Manage 2004; 27:370-378. 